\title{
Cholesterol Kinetics in Subjects with Bile Fistula Positive Relationship between Size of the Bile Acid Precursor Pool and Bile Acid Synthetic Rate
}

Charles C. Schwartz, Loren A. Zech, Julie M. VandenBroek, and Patricia S. Cooper

Department of Medicine, Medical College of Virginia, Virginia Commonwealth University, Richmond, Virginia 23298; and National Institutes of Health/National Heart, Lung, and Blood Institute, Bethesda, Maryland, 20892

\begin{abstract}
Our aim was to identify and quantitate cholesterol pools and transport pathways in blood and liver. By studying bile fistula subjects, using several types of isotopic preparations, simultaneous labeling of separate cholesterol pools and sampling all components of blood and bile at frequent intervals, we developed a comprehensive multicompartmental model for cholesterol within the rapidly miscible pool. Data in six components (bile acids, esterified cholesterol in whole plasma, and free cholesterol in blood cells, bile, $\alpha$ lipoproteins, and $\beta$ lipoproteins ) were modeled simultaneously with the SAAM program. The analysis revealed extensive exchange of free cholesterol between HDL and liver, blood cells, and other tissues. There was net free cholesterol transport from HDL to the liver in most subjects. The major organ that removed esterified cholesterol from blood was the liver. A large portion $(4,211 \mu \mathrm{mol})$ of total hepatic cholesterol comprised a pool that turned over rapidly $\left(t_{1 / 2}\right.$ of $\left.72 \mathrm{~min}\right)$ by exchanging mainly with plasma HDL and was the major source of bile acids and biliary cholesterol. Only $6 \%$ of hepatic newly synthesized cholesterol was used directly for bile acid synthesis: the analysis showed that $94 \%$ of newly synthesized cholesterol was partitioned into the large hepatic pool (putative plasma membrane free cholesterol) which exchanged rapidly with plasma lipoproteins. Bile acid synthetic rate correlated directly with the size of the large hepatic pool. In conclusion, hepatic and blood cholesterol pools and transports have been quantitated. HDL plays a central role in free cholesterol exchange/transport between all tissues and plasma. In humans, the metabolically active pool comprises a large portion of total hepatic cholesterol that, in part, regulates bile acid synthesis. (J. Clin. Invest. 1993. 91:923-938.) Key words: high density lipoprotein • blood cell cholesterol • esterified cholesterol $\bullet$ multicompartmental analysis $\bullet$ hepatic cholesterol
\end{abstract}

A portion of this study was presented at a joint meeting of the AAP/ American Society for Clinical Investigation/AFCR on 6 May 1990, Washington, DC.

Address correspondence to Dr. Charles C. Schwartz, Medical College of Virginia, Box 711, MCV Station, Richmond, Virginia 23298. All the absolute specific activity versus time values for any subject can be obtained from the corresponding author.

Received for publication 11 February 1992 and in revised form 9 September 1992.

J. Clin. Invest.

(C) The American Society for Clinical Investigation, Inc.

0021-9738/93/03/0923/16 \$2.00

Volume 91, March 1993, 923-938

\section{Introduction}

Free (unesterified) cholesterol (FC) ${ }^{1}$ is ubiquitous in human blood and tissues; especially enriched in FC are plasma membrane bilayers and lipoprotein surface monolayers. In blood and in some tissues, FC transport is very dynamic and can occur by diverse mechanisms involving lipoproteins, lipoprotein receptors, transfer/binding proteins, flip-flop, lateral membrane diffusion, aqueous diffusion, and micelles, among others. To add to the complexity, FC can be converted reversibly to esterified form (the major form of cholesterol in lipoproteins) and irreversibly to steroid hormones and bile acids. Cholesterol is the principal ingredient in two common disorders: atherosclerosis and gallstones.

The identification and magnitude of cholesterol transport pathways in the living whole organism are largely unknown. Hellman, Gould, Field, and Kurland were among the first to carry out in vivo studies in humans of cholesterol kinetics (14); Goodman, Noble, and Dell identified a rapidly miscible pool (cholesterol in blood, liver, intestine, and a few other organs) that exchanged slowly with two large side pools (5). Little is known about cholesterol transport between lipoproteins and specific tissues that comprise the rapidly miscible pool. In previous kinetic experiments in humans using isotopic mevalonic acid and isotopic FC in HDL or LDL, it was determined that plasma FC, probably in HDL, exchanged extensively with hepatic precursor compartments for biliary cholesterol secretion and bile acid synthesis, thus providing most of the substrate for these excretory pathways $(6,7)$. Also, there was rapid exchange of FC between HDL and $\beta$ lipoproteins (7). These experiments lacked the data to provide sensitivity for measurement of $(a)$ cholesterol transport between $\beta$ lipoproteins, liver, and other tissues, $(b)$ unidirectional (net) FC transport to or from HDL over and above the exchange between HDL, liver, and other tissues, and $(c)$ accurate tissue pool sizes since their estimates had wide limits. Based on insight gained from the previous experiments, the shortcomings were overcome by administration of multiple isotopes and then, in most current experiments, by separating HDL from $\beta$ lipoproteins immediately after collection of blood samples, analyzing blood cell cholesterol, collecting bile for analysis of cholesterol and bile acids, and analysis of plasma esterified cholesterol. These improvements in design allowed the acceptance of our hypothesis of net FC transport from HDL to a single precursor pool for both bile acid synthesis and biliary cholesterol secretion, and

1. Abbreviations used in this paper: $\mathrm{CBD}$, common bile duct; $\mathrm{DBED}$ dibenzylethylenediamine; EC, esterified cholesterol; FC, free cholesterol; FSD, fractional standard deviation; NSC, newly synthesized cholesterol; $U_{1}$, rate of cholesterol input. 
permitted quantitation of the size of this hepatic pool; we found that the latter varied in direct relation to the rate of bile acid synthesis. Furthermore, this series of studies provided additional evidence that HDL FC is the major pool of plasma cholesterol in direct communication with hepatic and extrahepatic tissue cholesterol pools.

\section{Methods}

Subjects. Nine experiments were carried out in five ambulatory volunteers with bile fistula at the Clinical Research Center, Medical College of Virginia; clinical information on these subjects is summarized in Tables I and II. Informed consent was obtained from each volunteer. They all had normal renal and liver function tests, a normal lipoprotein pattern on agarose gel, and excellent nutritional status: The range of body weight was $<1 \mathrm{~kg}$ in the $10 \mathrm{~d}$ preceding, during, and several days after all studies.

Four subjects were studied twice. In three subjects (I.D., E.B., and J.T.), the second experiment was started 1-3 d after the start of the first experiment. In subject R.T., the second experiment started $5 \mathrm{wk}$ after the start of the first. For at least $2 \mathrm{~d}$ before and during all nine experiments, bile was continuously collected by gravity siphonage from a Tor U-tube which was monitored every 15-60 min to assure complete collection by preventing blockage of the tube. Under these conditions, the bile fistula seemed to be complete throughout the experiment as evidenced by: $(a)$ acholic stools; $(b)$ constant bile lipid secretion from hour to hour; and $(c)$ the absence of $2^{\circ}$ bile acids. Furthermore, in subjects I.D. and J.T., bile acids were not present in duodenal aspirates collected for $90 \mathrm{~min}$ the day before the first experiment.

Each subject was administered two labeled compounds (Table II) simultaneously by vein at about 11 a.m. over a 1 -min period. The subjects fasted, except for water, for $12 \mathrm{~h}$ before and $6 \mathrm{~h}$ after administration of the labeled compounds. Blood samples, 4-7 ml each, were obtained at frequent intervals as shown in Figs. 1-3 and Table III. After the initial $6 \mathrm{~h}$, blood samples were obtained after at least $3 \mathrm{~h}$ of fasting.

All raw data from six previously published experiments were reanalyzed under the constraint of the knowledge (kinetic information) gained from the nine new experiments. The clinical information and methods used in these six experiments have been published (6).

Radiolabels. The DL $\left[5-{ }^{3} \mathrm{H}\right]$ mevalonic acid (dibenzylethylenediamine [DBED] salt $),\left[1,2-{ }^{3} \mathrm{H}\right]$ cholesterol, and $\left[4-{ }^{14} \mathrm{C}\right]$ cholesterol were obtained from NEN Research Products, Boston, MA, and stored at $-15^{\circ} \mathrm{C}$ in ethanol. Radiolabeled cholesterol was checked for purity by silicic acid column chromatography (8), thin layer chromatography (7), and recovery of radioactivity as cholesterol digitonide (9). The labeled cholesterol was not used if purity was $<94 \%$ by any of the three methods. Mevalonic acid was liberated from the DBED salt by the addition of $8.4 \%$ sodium bicarbonate and DBED was then extracted with diethyl ether. The aqueous solution was neutralized with $\mathrm{HCl}$, diluted to a volume of $10 \mathrm{ml}$ with sterile saline, passed through a $0.22-$ $\mu \mathrm{m}$ filter, assayed for radioactivity, and administered to subject E.H.I.

Cholesterol-labeled lipoproteins and albumin. Preparation of each labeled lipoprotein was carried out from a fasting sample of the subjects' blood obtained 1-3 d before the start of the experiment. The blood was collected in EDTA $(1 \mathrm{mg} / \mathrm{ml})$, immediately cooled to $5^{\circ} \mathrm{C}$, and the blood cells removed at $2,700 \mathrm{rpm}$ in a refrigerated centrifuge. Several 5-mm disks of filter paper (No. 1; Whatman Inc., Clifton, NJ) were placed in the bottom of sterile screw-top vials and impregnated under $\mathrm{N}_{2}$ with $\left[4-{ }^{14} \mathrm{C}\right]$ cholesterol or $\left[1,2-{ }^{3} \mathrm{H}\right]$ cholesterol in $100 \mu \mathrm{l}$ ethanol which was quickly evaporated by the gentle stream of $\mathrm{N}_{2}$. The subjects' fresh plasma $\left(20-30 \mathrm{ml}\right.$ at $\left.5^{\circ} \mathrm{C}\right)$ was immediately added and the vial was gently agitated in a $5^{\circ} \mathrm{C}$ water bath for $2 \mathrm{~h}$. Approximately $10-20 \%$ of the radioactivity applied to the filter paper disks was recovered in the plasma.

Table II lists the labeled compounds administered. VLDL labeled with $\left[1,2-{ }^{3} \mathrm{H}\right]$ cholesterol (subject R.T.I and R.T.II) was isolated from the top of ${ }^{3} \mathrm{H}$-labeled plasma after ultracentrifugation $\left(5^{\circ} \mathrm{C}\right)$ at $d$

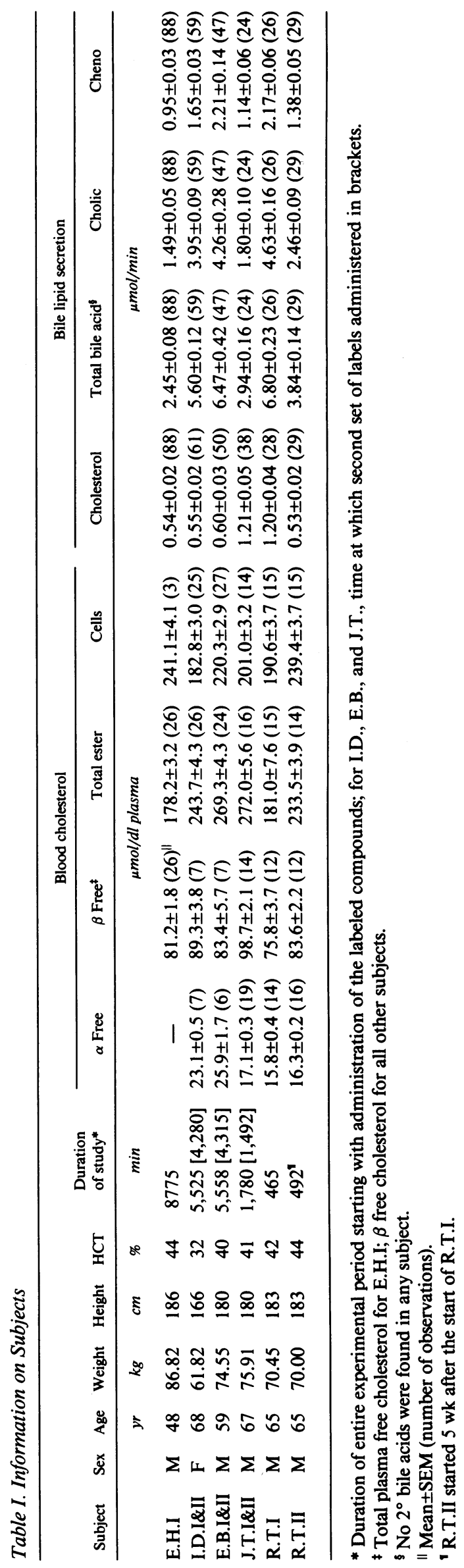




\begin{tabular}{|c|c|c|c|}
\hline Subject & Labeled compounds administered ${ }^{*}$ & $\begin{array}{l}\text { Amount of } \\
\text { radioactivity } \\
\text { administered }\end{array}$ & Comments \\
\hline & & $d p m \times 10^{-6}$ & \\
\hline E.H.I & $\begin{array}{l}\text { Albumin-free }\left[4-{ }^{14} \mathrm{C}\right] \text { cholesterol (particulate) } \\
\text { DL }\left[5-{ }^{3} \mathrm{H}\right] \text { mevalonic acid }\end{array}$ & $\begin{array}{r}35.000 \\
477.300\end{array}$ & $\begin{array}{l}\text { T tube placement in common bile duct (CBD), just below } \\
\text { cystic duct, } 4.5 \text { wk before study. Surgery for benign } \\
\text { mass/abscess drainage head of pancreas. Total bile fistula } \\
\text { for } 5 \mathrm{~d} \text { before, then throughout the study. History of } \\
\text { pancreatitis probably secondary to chronic alcoholism. } \\
\text { Abstinent for } 3 \text { mo and only medication was } \mathrm{NaHCO}_{3} \text {, } \\
600 \mathrm{mg} / \mathrm{d} \text {, for } 2 \text { wk before study. }\end{array}$ \\
\hline \multirow[t]{3}{*}{ I.D.I } & HDL-free $\left[1,2-{ }^{3} \mathrm{H}\right]$ cholesterol & 38.730 & \multirow{3}{*}{$\begin{array}{l}\text { Cholecystectomy, CBD exploration, and T tube placement } \\
2.5 \text { wk before study. Total bile fistula for all but } 30 \mathrm{~h} \\
\text { after surgery, then throughout study. Meds: } \mathrm{NaHCO}_{3} 600 \\
\mathrm{mg} / \mathrm{d} \text {. Alkaline phosphatase } 150 \mathrm{U} / \mathrm{dl} \text { (normal }<100\end{array}$} \\
\hline & HDL-esterified $\left[1,2-{ }^{3} \mathrm{H}\right]$ cholesterol & 0.479 & \\
\hline & LDL-free $\left[4-{ }^{14} \mathrm{C}\right]$ cholesterol & 1.020 & \\
\hline \multirow[t]{3}{*}{ I.D.II } & HDL-free $\left[4-{ }^{14} \mathrm{C}\right]$ cholesterol & 0.723 & \multirow[t]{3}{*}{$\mathrm{U} / \mathrm{dl})$} \\
\hline & HDL-esterified $\left[4-{ }^{14} \mathrm{C}\right]$ cholesterol & 0.034 & \\
\hline & LDL-free $\left[1,2-{ }^{3} \mathrm{H}\right]$ cholesterol & 26.330 & \\
\hline \multirow[t]{3}{*}{ E.B.I } & HDL-free $\left[1,2-{ }^{3} \mathrm{H}\right]$ cholesterol & 47.259 & \multirow{6}{*}{$\begin{array}{l}\text { Cholecystectomy, CBD exploration, and } \mathrm{T} \text { tube placement } \\
5 \text { wk before study. Total bile fistula for } 4 \mathrm{~d} \text { before, then } \\
\text { throughout the study. Meds: } \mathrm{NaHCO}_{3} 600 \mathrm{mg} / \mathrm{d} \text {. }\end{array}$} \\
\hline & HDL-esterified $\left[1,2-{ }^{3} \mathrm{H}\right]$ cholesterol & 0.420 & \\
\hline & LDL-free $\left[4-{ }^{14} \mathrm{C}\right]$ cholesterol & 1.323 & \\
\hline \multirow[t]{3}{*}{ E.B.II } & HDL-free $\left[4-{ }^{14} \mathrm{C}\right]$ cholesterol & 0.395 & \\
\hline & HDL-esterified ${ }_{3}\left[4-{ }^{14} \mathrm{C}\right]$ cholesterol & 0.016 & \\
\hline & LDL-free $\left[1,2-{ }^{3} \mathrm{H}\right]$ cholesterol & 57.479 & \\
\hline \multirow[t]{2}{*}{ J.T.I } & Albumin-free $\left[4-{ }^{14} \mathrm{C}\right]$ cholesterol (exchange) ${ }^{8}$ & 3.351 & \multirow{5}{*}{$\begin{array}{l}\text { Diabetic; Meds: } 45 \mathrm{U} \text { NPH insulin/d, Dalmane } 15 \mathrm{mg} / \mathrm{d} \\
\text { and ASA } 300 \mathrm{mg} / \mathrm{d} \text {. Total bile fistula for } 2 \mathrm{~d} \text { before start } \\
\text { of study; U tube inserted } 6 \text { wk before the study; inserted } \\
\text { for repair of benign CBD stricture; tube irrigated daily. } \\
\text { Cholecystectomy } 4 \text { yr previously. Triglyceride } 128 \mathrm{mg} / \mathrm{dl} \text {. }\end{array}$} \\
\hline & VLDL/LDL-free $\left[1,2-{ }^{3} \mathrm{H}\right]$ cholesterol & 33.636 & \\
\hline \multirow[t]{3}{*}{ J.T.II } & HDL-free $\left[1,2-{ }^{3} \mathrm{H}\right]$ cholesterol & 7.873 & \\
\hline & HDL-esterified $\left[1,2-{ }^{3} \mathrm{H}\right]$ cholesterol & 0.072 & \\
\hline & Albumin-free $\left[4-{ }^{14} \mathrm{C}\right]$ cholesterol (exchange) ${ }^{8}$ & 3.032 & \\
\hline \multirow[t]{2}{*}{ R.T.I } & VLDL-free $\left[1,2-{ }^{3} \mathrm{H}\right]$ cholesterol & 34.975 & \multirow[b]{2}{*}{$\begin{array}{l}\text { T tube inserted during cholecystectomy and CBD } \\
\text { exploration } 2.5 \text { weeks before start of study. Pigment } \\
\text { gallstones on gross exam. Total bile fistula for } 10 \mathrm{~d} \text { before } \\
\text { start of study. No alcohol for } 2 \mathrm{y} \text {; previous alcoholism; } \\
\text { chronic obstructive pulmonary disease. }\end{array}$} \\
\hline & LDL-free $\left[4-{ }^{14} \mathrm{C}\right]$ cholesterol & 1.726 & \\
\hline \multirow[t]{3}{*}{ R.T.II } & HDL-free $\left[4-{ }^{14} \mathrm{C}\right]$ cholesterol ${ }^{\| \prime}$ & 1.462 & \multirow{3}{*}{$\begin{array}{l}\text { See R.T.I. Total bile fistula for } 5 \mathrm{~d} \text { before start of study. T } \\
\text { tube clamped for } 30 \text { of the } 35 \mathrm{~d} \text { between R.T.I and R.T.II } \\
\text { studies. }\end{array}$} \\
\hline & HDL-esterified $\left[4-{ }^{14} \mathrm{C}\right]$ cholesterol ${ }^{11}$ & 0.013 & \\
\hline & VLDL-free $\left[1,2-{ }^{3} \mathrm{H}\right]$ cholesterol & 14.556 & \\
\hline
\end{tabular}

\footnotetext{
* Lipoproteins isolated by ultracentrifugation of labeled autologous plasma. $\mathrm{VLDL}=d \leq 1.006 ; \mathrm{VLDL} / \mathrm{LDL}=d \leq 1.062 ; \mathrm{LDL}=1.019<d$ $\leq 1.062 ; \mathrm{HDL}=1.065<d \leq 1.21 \mathrm{~g} / \mathrm{ml}$.

${ }^{\ddagger}$ Administered simultaneously in each subject.

${ }^{8}$ No isotopic esterified cholesterol detected in preparations of albumin containing $\left[{ }^{14} \mathrm{C}\right]$ cholesterol. Albumin-free $\left[{ }^{14} \mathrm{C}\right]$ cholesterol in particulate form or prepared by exchange and filtration (see Methods).

$" \mathrm{HDL}=1.070<d \leq 1.21 \mathrm{~g} / \mathrm{ml}$.
}

$=1.006 \mathrm{~g} / \mathrm{ml}$. Each VLDL-free $\left[1,2-{ }^{3} \mathrm{H}\right]$ cholesterol preparation was passed through $0.45-\mu \mathrm{m}$ and then $0.22-\mu \mathrm{m}$ filters immediately before administration to the subject. A mixture of VLDL and LDL labeled with $\left[1,2,{ }^{3} \mathrm{H}\right]$ cholesterol was given to J.T.I. The VLDL/LDL was isolated from the top of ${ }^{3} \mathrm{H}$-labeled plasma ultracentrifuged at $d=1.062$ $\mathrm{g} / \mathrm{ml}$. It was then dialyzed overnight against $0.15 \mathrm{M} \mathrm{NaCl}$ at $5^{\circ} \mathrm{C}$ con-

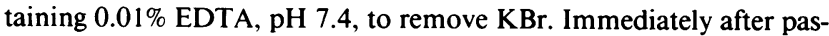
sage through $0.45-$ and $0.22-\mu \mathrm{m}$ filters the labeled preparation was administered to the subject. LDL labeled with $\left[4-{ }^{14} \mathrm{C}\right]$ cholesterol (E.B.I, I.D.I, and R.T.I) or $\left[1,2-{ }^{3} \mathrm{H}\right]$ cholesterol (E.B.II and I.D.II) was separated from labeled whole plasma by successive ultracentrifugation at $d$ $=1.019$ and $1.063 \mathrm{~g} / \mathrm{ml}$, then dialyzed and filtered as above. HDL labeled with $\left[1,2-{ }^{3} \mathrm{H}\right]$ cholesterol (E.B.I, I.D.I, and J.T.II) or $\left[4-{ }^{14} \mathrm{C}\right]-$ cholesterol (E.B.II, I.D.II, and R.T.II) was isolated from labeled whole plasma by sequential ultracentrifugation at $d=1.065$ (or 1.070 in R.T.II ) and $1.21 \mathrm{~g} / \mathrm{ml}$; dialysis and filtration were then carried out.
Normal serum albumin (human, 25\%, USP; Cutter Laboratories, Inc., Berkeley, $\mathrm{CA}$, diluted to $12.5 \%$ with sterile $0.15 \mathrm{M} \mathrm{NaCl}$ ) was coupled, by exchange, with $\left[4-{ }^{14} \mathrm{C}\right]$ cholesterol for administration to J.T.; $15 \mathrm{ml}$ of $12.5 \%$ albumin was added to ${ }^{14} \mathrm{C}$-cholesterol impregnated filter paper disks under $\mathrm{N}_{2}$, as above. The ${ }^{14} \mathrm{C}$-cholesterol-albumin solution was decanted after $3 \mathrm{~h}$ and administered to the subject (J.T.I and J.T.II, Table II ) after passage through two $0.22-\mu \mathrm{m}$ filters connected in series. In subject E.H.I, $\left[4-{ }^{14} \mathrm{C}\right]$ cholesterol was administered in particulate form with albumin. The ${ }^{14} \mathrm{C}$-cholesterol in $0.07 \mathrm{ml}$ of absolute ethanol was slowly added to $15 \mathrm{ml}$ of human albumin (Cutter Laboratories, Inc.) with gentle mixing and administered within $2 \mathrm{~h}$ without filtration.

An aliquot of each lipoprotein preparation containing isotopic cholesterol was obtained immediately before administration to the subject. Analysis revealed a lipid composition identical to that of the corresponding native lipoprotein. Between 95 and $100 \%$ of the isotopic cho- 
Table III. Subject R.T.I (Bile Fistula), Simultaneously Administered VLDL-free[1,2- ${ }^{3} \mathrm{H}$ Cholesterol and LDL-free $\left[4-{ }^{14} \mathrm{CJCholesterol} ;{ }^{3} \mathrm{H}\right.$ and ${ }^{14} \mathrm{C}$-specific Activities Expressed as Fraction of Dose per Micromole

\begin{tabular}{|c|c|c|c|c|c|c|c|c|c|c|c|c|}
\hline \multirow[b]{2}{*}{ Time } & \multicolumn{2}{|c|}{$\beta$ (VLDL/LDL)FC } & \multicolumn{2}{|c|}{$\alpha(\mathrm{HDL})-\mathrm{FC}$} & \multicolumn{2}{|c|}{$\begin{array}{c}\text { Biliary } \\
\text { cholesterol }\end{array}$} & \multicolumn{2}{|c|}{ Cholic acid } & \multicolumn{2}{|c|}{ Blood cell FC } & \multicolumn{2}{|c|}{ Plasma-EC } \\
\hline & ${ }^{3} \mathrm{H}$ & ${ }^{14} \mathrm{C}$ & ${ }^{3} \mathrm{H}$ & ${ }^{14} \mathrm{C}$ & ${ }^{3} \mathrm{H}$ & ${ }^{14} \mathrm{C}$ & ${ }^{3} \mathrm{H}$ & ${ }^{14} \mathrm{C}$ & ${ }^{3} \mathrm{H}$ & ${ }^{14} \mathrm{C}$ & ${ }^{3} \mathrm{H}$ & ${ }^{14} \mathrm{C}$ \\
\hline $\min$ & \multicolumn{12}{|c|}{ fraction of dose $/ \mu \mathrm{mol} \times 10^{-3}$} \\
\hline 7 & 0.420 & 0.401 & 0.180 & 0.142 & 0.000 & 0.000 & 0.000 & 0.001 & 0.008 & 0.007 & 0.000 & 0.001 \\
\hline 15 & 0.374 & 0.364 & 0.186 & 0.165 & 0.000 & 0.000 & 0.001 & 0.000 & 0.010 & 0.010 & 0.001 & 0.001 \\
\hline 22 & 0.314 & 0.310 & 0.189 & 0.183 & 0.004 & 0.006 & 0.002 & 0.003 & 0.012 & 0.011 & 0.003 & 0.002 \\
\hline 32 & 0.280 & 0.274 & 0.183 & 0.174 & 0.016 & 0.018 & 0.007 & 0.005 & 0.017 & 0.016 & 0.004 & 0.005 \\
\hline 53 & 0.218 & 0.220 & 0.135 & 0.142 & 0.029 & 0.035 & 0.017 & 0.016 & 0.022 & 0.023 & 0.006 & 0.005 \\
\hline 75 & 0.163 & 0.149 & 0.111 & 0.094 & 0.051 & 0.050 & 0.030 & 0.030 & 0.027 & 0.027 & 0.007 & 0.006 \\
\hline 93 & 0.135 & 0.141 & 0.116 & 0.089 & 0.060 & 0.064 & 0.043 & 0.042 & 0.028 & 0.028 & 0.008 & 0.007 \\
\hline 113 & 0.111 & 0.114 & 0.082 & 0.096 & 0.064 & 0.068 & 0.056 & 0.062 & 0.030 & 0.029 & 0.009 & 0.010 \\
\hline 135 & 0.096 & 0.095 & - & 0.069 & 0.070 & 0.074 & 0.060 & 0.060 & 0.034 & 0.034 & 0.010 & - \\
\hline 153 & 0.086 & 0.088 & 0.076 & 0.064 & 0.066 & 0.070 & 0.064 & 0.067 & 0.034 & 0.034 & 0.010 & 0.010 \\
\hline 173 & 0.078 & 0.077 & 0.072 & 0.058 & 0.060 & 0.061 & 0.059 & 0.058 & 0.037 & 0.036 & 0.011 & 0.010 \\
\hline 215 & 0.059 & 0.062 & 0.051 & 0.051 & 0.055 & 0.057 & 0.056 & 0.058 & 0.039 & 0.041 & 0.011 & 0.013 \\
\hline 255 & 0.056 & 0.058 & 0.061 & 0.046 & 0.048 & 0.049 & 0.049 & 0.046 & 0.040 & 0.042 & 0.014 & 0.015 \\
\hline 345 & 0.045 & 0.043 & 0.046 & 0.044 & 0.040 & 0.040 & 0.040 & 0.040 & 0.039 & 0.039 & 0.013 & 0.014 \\
\hline 448 & 0.038 & 0.037 & 0.040 & 0.041 & 0.032 & 0.033 & 0.032 & 0.031 & 0.039 & 0.040 & 0.015 & 0.014 \\
\hline
\end{tabular}

lesterol was unesterified (Table II); $0.0-0.3 \%$ (mean $0.18 \%$ ) of the ${ }^{3} \mathrm{H}$ or ${ }^{14} \mathrm{C}$-cholesterol was esterified in the VLDL and LDL preparations (data not shown); 0.9-4.5\% (mean $=1.9 \%$ ) was esterified in the HDL preparations. In the preparations of albumin containing ${ }^{14} \mathrm{C}$-cholesterol (E.H. and J.T.), $100 \%$ of the ${ }^{14} \mathrm{C}$-activity was unesterified. Each preparation of LDL or VLDL migrated as a single band on agarose gel electrophoresis (10) and paralleled the corresponding lipoprotein standard. There was a relatively faint pre-Beta band in each HDL preparation. Treatment of $\mathrm{HDL}$ preparations with heparin- $\mathrm{MnCl}_{2}$ before electrophoresis completely eliminated this pre-Beta band, presumably $\mathrm{Lp}(\mathrm{a})$, but did not change HDL migration. Agarose gels ( $2 \mathrm{~mm}$ thick) were also sliced and assayed for radioactivity. For LDL and VLDL preparations, $>90 \%$ of the radioactivity in the gel was associated with the appropriate lipoprotein fraction; remaining radioactivity was spread over the entire gel. In HDL preparations, 4-5\% of the radioactivity was concentrated in the pre-Beta band and $84-89 \%$ in HDL; the remainder was evenly distributed throughout the gel. Furthermore, $>85 \%$ of the radioactivity floated in the appropriate density range when an aliquot of each labeled lipoprotein preparation was reultracentrifuged.

Analytic procedures. Some blood samples were collected in heparinized ( 143 USP U) tubes and were immediately centrifuged at 3,000 rpm at $5^{\circ} \mathrm{C}$ for $5 \mathrm{~min}$ to separate plasma from cells. The plasma was immediately treated with heparin- $\mathrm{MnCl}_{2}$ to precipitate the $\beta$ lipoproteins (11). After centrifugation for $5 \mathrm{~min}$, the supernate (containing $\alpha$-HDL) was decanted into chloroform:methanol. The precipitate was resuspended and washed twice to remove all traces of $\alpha$-HDL. The isolated $\alpha$ and $\beta$ fractions were periodically monitored by agarose gel electrophoresis and always found to be free of contamination. In E.H., E.B., and I.D., most blood samples were collected on EDTA, $1 \mathrm{mg} / \mathrm{ml}$, $5^{\circ} \mathrm{C}$; after rapid separation of blood cells, the whole plasma was added to chloroform:methanol without separation of lipoproteins; in J.T., R.T.I, and R.T.II, only one to two whole plasma samples were analyzed without separation of lipoproteins. Blood cells were washed three times with twofold volume of $0.15 \mathrm{M} \mathrm{NaCl}\left(5^{\circ} \mathrm{C}\right)$. Throughout all procedures described above the samples were maintained at $5^{\circ} \mathrm{C}$ and processed quickly to retard exvivo lipid exchange and esterification. Immediately after isolation, the whole plasma, $\alpha$ lipoprotein, $\beta$ lipoprotein, blood cell, and bile samples were added to $20 \mathrm{vol}$ of chloroform:methanol (2:1, vol:vol).
Chloroform and methanol phases were separated by the addition of one-fifth volume of water (12). The chloroform phase was subjected to silicic acid column chromatography to separate free from esterified cholesterol (8). Free cholesterol mass was determined by gas liquid chromatography using coprostanol as the internal standard. The stationary phase was 3\% SP-2401 (Supelco, Inc., Bellefonte, PA). Carrierfree cholesterol was added to an aliquot of the free cholesterol fraction; the digitonide was formed, dissolved in methanol, and assayed for ${ }^{3} \mathrm{H}$ and ${ }^{14} \mathrm{C}$ activity by liquid scintillation counting ( 1217 Rackbeta; LKB Instruments, Inc., Gaithersburg, MD). The external standard method was used for quench correction; each sample was counted for $20 \mathrm{~min}$. Esterified cholesterol was hydrolyzed with $5 \% \mathrm{KOH}$ for $1 \mathrm{~h}$, neutralized with $\mathrm{HCl}$, and the liberated free cholesterol precipitated as the digitonide; mass was determined colorimetrically on an aliquot of the digitonide (9); another aliquot was dissolved in methanol and assayed for ${ }^{3} \mathrm{H}$ and ${ }^{14} \mathrm{C}$ activity. The esterified cholesterol in $\alpha$ and $\beta$ lipoprotein fractions (isolated in J.T. and R.T.) were pooled for the analysis so that all esterified cholesterol data represents whole plasma.

Determination of masses of individual bile acids by gas chromatography and of radioactivity in cholic acid and in chenodeoxycholic acid were carried out on the methanol phase of the original chloroform:methanol extract of bile, as described previously (6). Procedural loss of each bile acid species was estimated using taurine- and glycine-conjugated bile acid standards and the final calculations corrected accordingly. Loss of cholic and chenodeoxycholic acids averaged $15 \%$ (range $8-21 \%$ ). DL $\left[5-{ }^{3} \mathrm{H}\right]$ mevalonic acid was given to E.H.I. Bile acid radioactivities in E.H.I were corrected for loss of ${ }^{3} \mathrm{H}$ : $(a)$ during the conversion of cholesterol to bile acids and $(b)$ attributable to the analytic procedure as described previously (6).

\section{Results}

Blood cholesterol concentrations and bile lipid secretion rates. The blood cholesterol concentrations are shown in Table I. In excess of $99.0 \%$ of cholesterol in blood cells was free (unesterified). Blood cell FC content is expressed as $\mu \mathrm{mol} / 100 \mathrm{ml}$ plasma and was calculated from the hematocrit and $\mu \mathrm{mol}$ FC per ml packed blood cells. In I.D. and E.B., whole plasma FC concentration (not shown) was essentially identical to the sum 
of $\alpha$-FC plus $\beta$-FC. In no subject did the cholesterol concentration of any component of blood change during the experiment. Likewise, the biliary cholesterol and bile acid secretion rates were constant in each subject as reflected by the small statistical variance (Table I).

Specific activity data. The specific activities of whole plasma FC, plasma esterified cholesterol (EC), biliary cholesterol, and cholic acid in subject E.H.I are shown in Fig. 1. Blood cell radioactivity was not measured. Chenodeoxycholic acid ${ }^{3} \mathrm{H}$ and ${ }^{14} \mathrm{C}$ specific activities are not shown in E.H.I or in the other subjects since they were virtually identical to cholic acid at all times as noted previously in bile fistula subjects (13).

After $\left[{ }^{3} \mathrm{H}\right]$ mevalonic acid administration to E.H.I ( upper panel of Fig. 1) there were at least 15 min before appearance of radioactivity in all samples. The delay was $\sim 4$ min longer for cholic acid than for biliary cholesterol. After the delay period the rate of build-up of radioactivity was most rapid in bile acids followed by biliary cholesterol, plasma FC, and then plasma EC. The peak specific activity was highest and earliest in the bile acids. Bile acid and biliary cholesterol specific activities became similar after $400 \mathrm{~min}$; however, after $600 \mathrm{~min}$, bile acid specific activity had crossed over the biliary cholesterol specific activity and remained slightly lower than biliary cholesterol.
Both bile acid and biliary cholesterol merged with plasma FC within $800 \mathrm{~min}$, after which plasma FC and biliary cholesterol specific activities were essentially identical through $8,775 \mathrm{~min}$. The plasma EC specific activity followed that of plasma FC in a classic product-precursor fashion, respectively.

The cholic acid and cholesterol specific activities after particulate ${ }^{14} \mathrm{C}$-FC administration to E.H.I are shown in the lower panel of Fig. 1. As opposed to the 25-min delay before ${ }^{3} \mathrm{H}$ appearance in biliary cholesterol of E.H.I, the delay for ${ }^{14} \mathrm{C}$ activity was $\sim 15 \mathrm{~min}$ and was similar for biliary cholesterol and bile acids. Bile acid ${ }^{14} \mathrm{C}$ specific activity was the same or slightly lower than that of biliary cholesterol throughout the $8,775 \mathrm{~min}$. The relatively constant plasma FC specific activity from 150 to $500 \mathrm{~min}$ reflects the particulate form of a large portion of the administered ${ }^{14} \mathrm{C}$-FC; immediately after administration, a large portion of the ${ }^{14} \mathrm{C}-\mathrm{FC}$ tracer is taken up by the reticuloendothelial system and most is gradually released into plasma during the subsequent $10 \mathrm{~h}$ (14). This "particulate" form of ${ }^{14} \mathrm{C}$-FC tracer is consistent with the model as shown below.

In a previous publication regarding subjects administered isotopic FC-albumin in particulate form, we reported that plasma FC specific activities were higher than specific activities
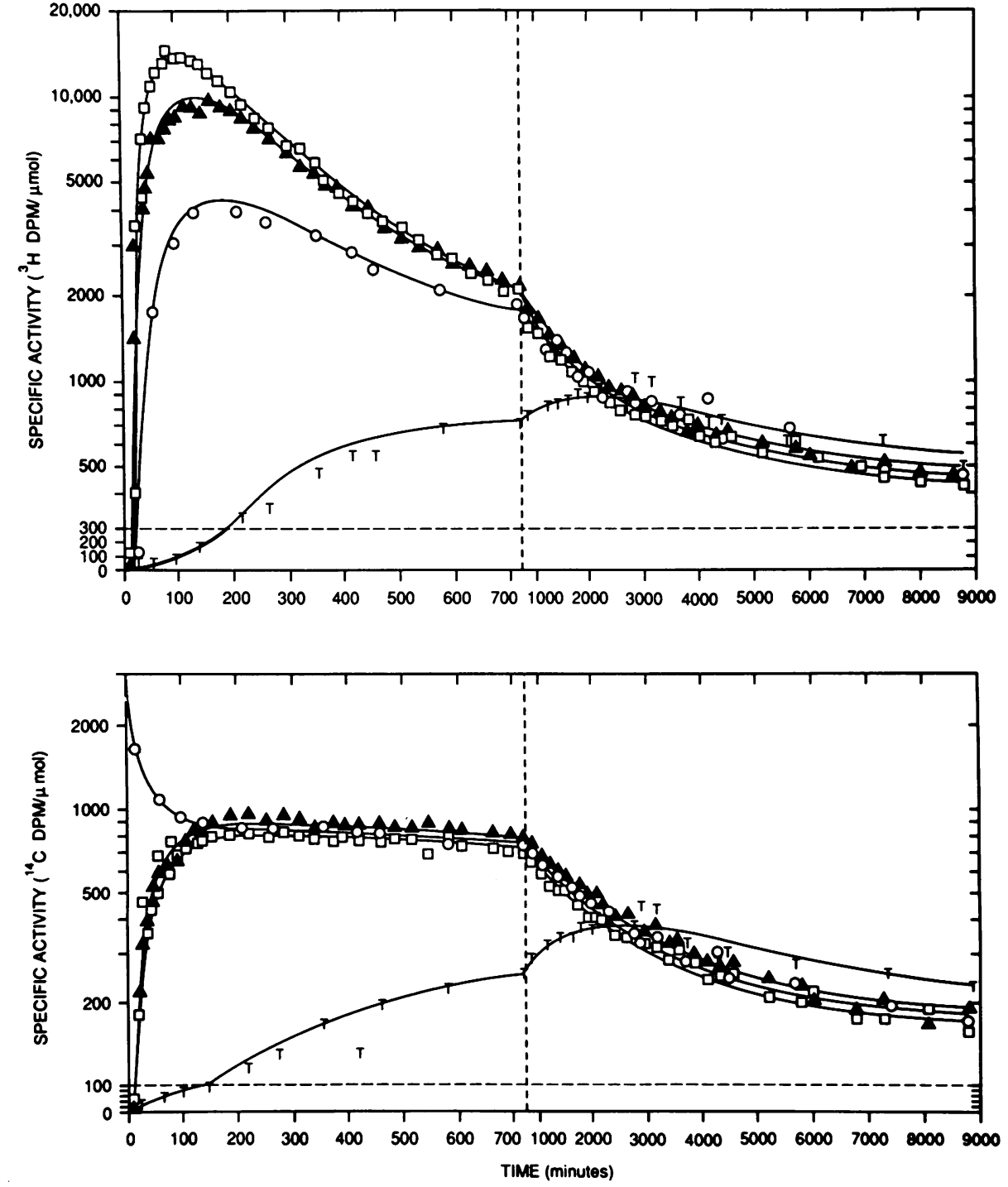

Figure 1. Subject E.H.I; specific activity time courses after simultaneous administration of ${ }^{3} \mathrm{H}$-mevalonic acid ( upper) and albumin containing free ${ }^{14} \mathrm{C}$-cholesterol in particulate form (lower). $O$, whole plasma FC; $T$, whole plasma EC; $\Delta$, biliary cholesterol; $\square$, cholic acid. Each solid line represents the computer simulation of the specific activity data in the corresponding compartment using the model shown in Fig. 5. The ${ }^{3} \mathrm{H}$ and ${ }^{14} \mathrm{C}$ specific activity values and observed masses were simultaneously fit to one set of parameter solutions. A dashed line represents change in scale. For purpose of graphic clarity, only alternate values for biliary cholesterol and cholic acid are plotted between 105 and 3,500 $\mathrm{min}$. 

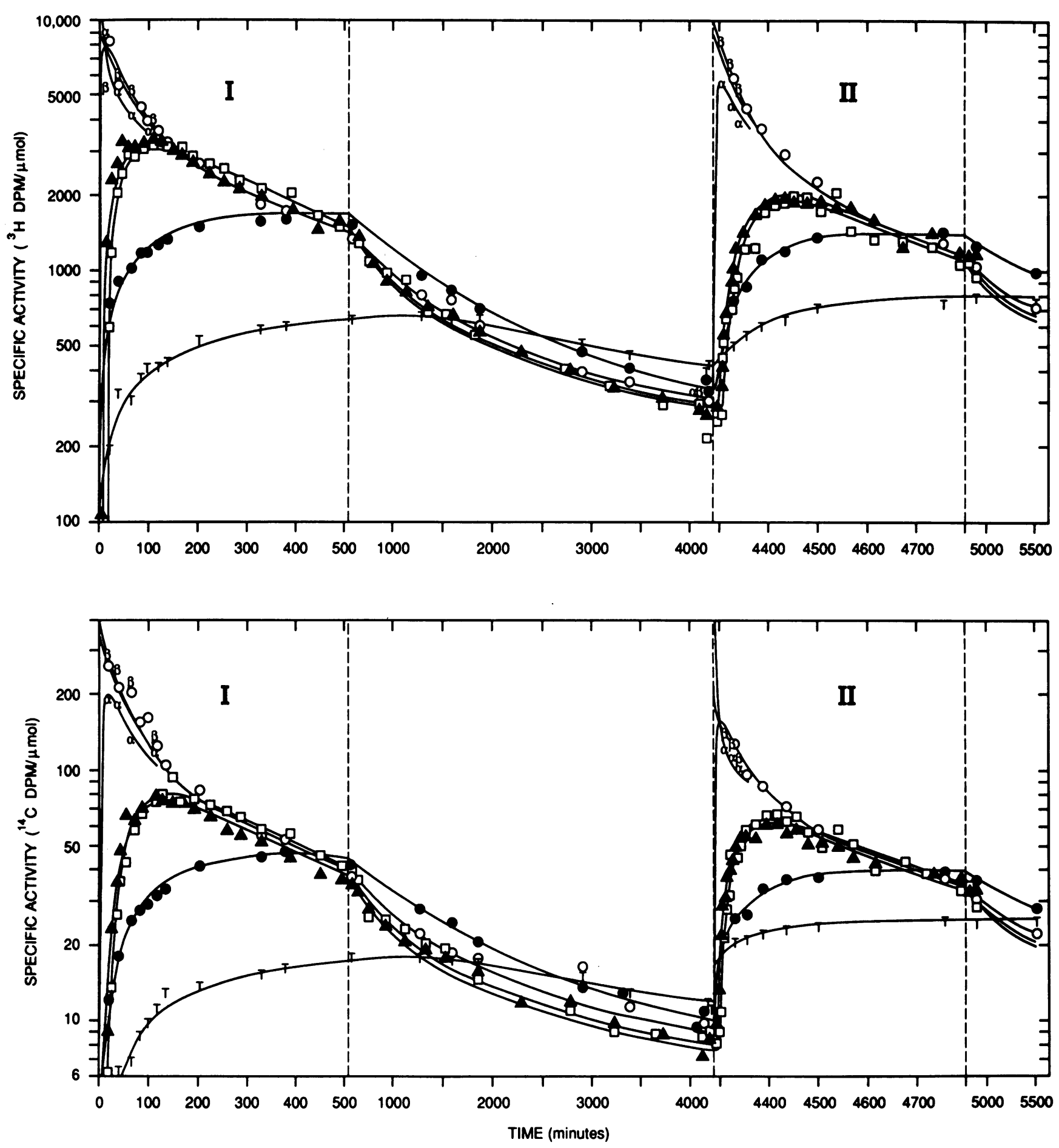

Figure 2. Subject I.D.; specific activity - time courses. In part I, HDL-free ${ }^{3} \mathrm{H}$-cholesterol ( upper) and LDL-free ${ }^{14} \mathrm{C}-$ cholesterol (lower) were administered simultaneously at time 0 . Part II was started 4,280 min later when LDL-free ${ }^{3} \mathrm{H}$-cholesterol (upper) and $\mathrm{HDL}$-free ${ }^{14} \mathrm{C}$-cholesterol (lower) were simultaneously administered. During the initial 1-2 h of both parts, three to four blood samples were obtained to rapidly isolate $\alpha$-HDL and $\beta$-VLDL/LDL. Otherwise, lipoproteins were not isolated from blood samples. $\alpha, \alpha$-HDL FC; $\beta, \beta$-VLDL/LDL FC; $O$, whole plasma FC; $T$, whole plasma EC; $\bullet$, blood cell FC; $\Delta$, biliary cholesterol; $\square$, cholic acid. Each solid line represents the computer simulation of the specific activity data in the corresponding compartment using the model shown in Fig. 4. All data in I.D. $\left({ }^{3} \mathrm{H}\right.$ - and ${ }^{14} \mathrm{C}$-specific activities and observed masses in parts I and II) were simultaneously fit to one set of parameter solutions. A dashed line represents change in time scale.

of biliary cholesterol and bile acids throughout the experiment (6). After isotopic mevalonic acid administration, as we also reported, plasma FC specific activities were higher than the bile components after $750 \mathrm{~min}$. $5 \alpha$-cholestane was used as the in- ternal standard for gas chromatography in those experiments and we subsequently found that there is a minor sterol present in plasma with the same retention time. This resulted in 12$17 \%$ underestimation of plasma cholesterol mass and overesti- 

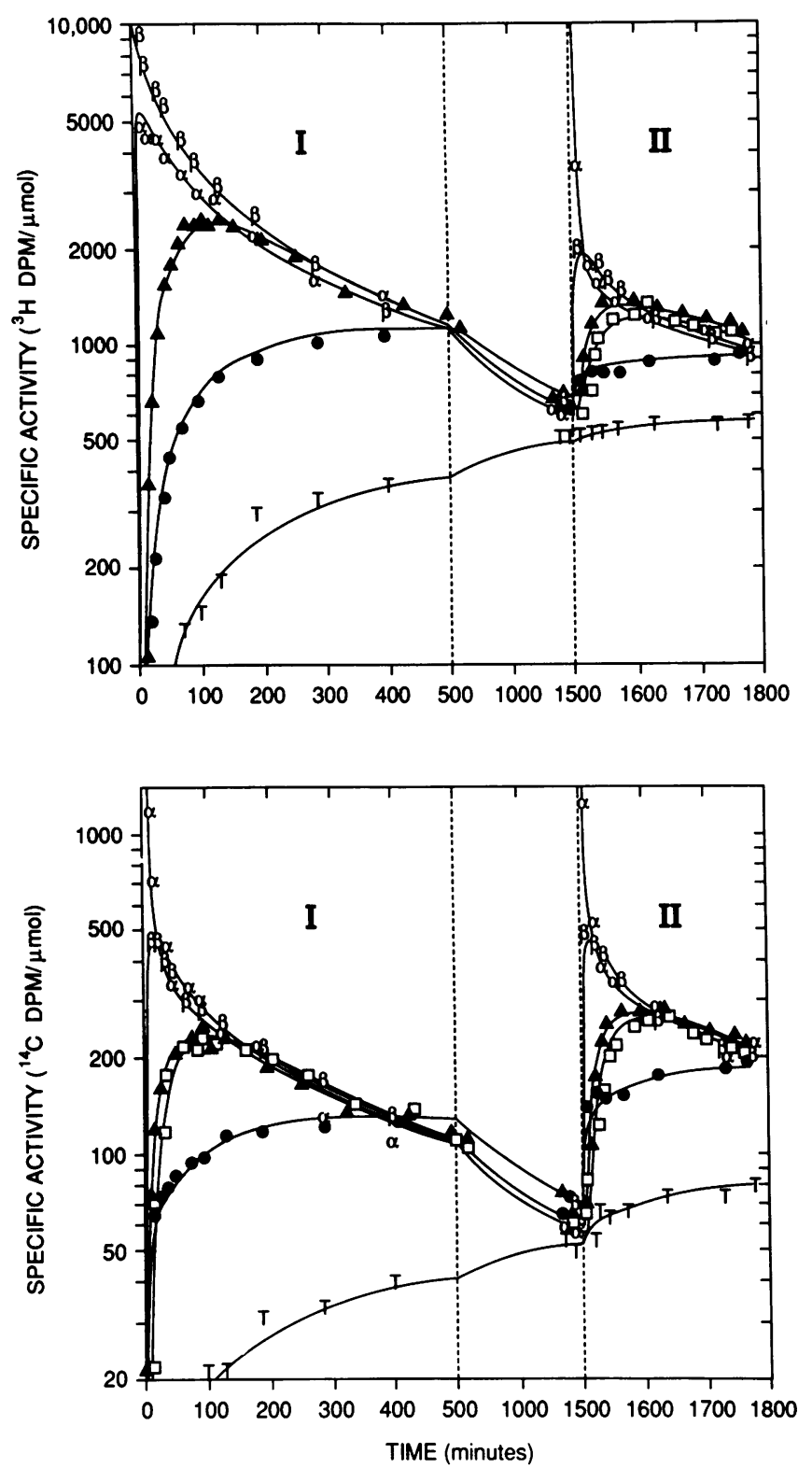

Figure 3. Subject J.T.; specific activity - time courses. In part I, VLDL/LDL-free ${ }^{3} \mathrm{H}$-cholesterol ( upper) and albumin containing free ${ }^{14} \mathrm{C}$-cholesterol (lower) were administered simultaneously at time 0 . Part II was started 1,492 min later when HDL-free ${ }^{3} \mathrm{H}$-cholesterol (upper) and albumin containing free ${ }^{14} \mathrm{C}$-cholesterol (lower) were simultaneously administered. Albumin containing free ${ }^{14} \mathrm{C}$-cholesterol (tracer) was prepared by exchange and filtration (see Methods). $\beta$ and $\alpha$ lipoproteins were rapidly isolated from all blood samples. $\alpha, \alpha$-HDL FC; $\beta, \beta$-VLDL/LDL FC; $T$, whole plasma EC; $\bullet$, blood cell FC; $\wedge$, biliary cholesterol; $\square$, cholic acid. Cholic acid data not shown in upper-I panel for purpose of graphic clarity. Lines as described in Fig. 2 legend. All data in J.T. were simultaneously fit to one set of parameter solutions using the model shown in Fig. 4.

mation of specific activity. When corrected, the plasma FC specific activities in the previous publication were essentially identical to biliary cholesterol specific activities at all times after the initial period of equilibration as also observed in the new subject, E.H.I (Fig. 1).

I.D.I and E.B.I were administered HDL- ${ }^{3} \mathrm{H}-\mathrm{FC}$ plus LDL${ }^{14} \mathrm{C}-\mathrm{FC}$ followed in $3 \mathrm{~d}$ by a second experiment in which I.D.II and E.B.II received HDL- ${ }^{14} \mathrm{C}-\mathrm{FC}$ plus LDL- ${ }^{3} \mathrm{H}-\mathrm{FC}$. The specific activities observed in I.D. are shown in Fig. $2,{ }^{3} \mathrm{H}$ data in the upper panel. The specific activities in E.B. (not shown) followed patterns identical to I.D. During the initial $100 \mathrm{~min}$ after each administration of labeled compounds to I.D. and E.B., three to four plasma samples were used to isolate $\alpha$ and $\beta$ lipoprotein FC. In addition, a large number of whole plasma samples were extracted for FC and EC analysis without isolation of lipoproteins throughout the entire I.D. and E.B. experiments.

For 30 min after administration of isotopic FC in HDL (Fig. 2, upper-I and lower-II) there was a precipitous decline in $\alpha$-FC specific activity. The $\beta$-FC specific activity rapidly increased and reached that of the $\alpha$-FC by $30 \mathrm{~min}$. Beyond 30 min, $\beta$-FC specific activity was slightly higher than $\alpha$-FC. After administration of isotopic FC in LDL (Fig. 2, upper-II and lower-I) there was a gradual decline in $\beta$-FC specific activity. The $\alpha$-FC specific activity rapidly increased but the peak was low and did not intersect the $\beta$-FC. These $\alpha$-FC and $\beta$-FC specific activity relationships are identical to those observed previously (7). Whole plasma FC specific activities were nearly identical to $\beta$-FC after the initial $30 \mathrm{~min}$ of each experiment reflecting the high proportion that $\beta$-FC mass contributes to whole plasma FC mass (Table I).

Biliary cholesterol and bile acid specific activities increased rapidly after an initial delay of 10-20 min after administration of isotopic FC in HDL and LDL (Fig. 2). Bile acid specific activities were lower than biliary cholesterol during the initial incline suggesting a longer delay for bile acids. The peak biliary cholesterol and peak bile acid specific activities were reached 90-140 min after administration of labeled compounds. From 100 to $500 \mathrm{~min}$ there was a trend for bile acid specific activity to be slightly higher than biliary cholesterol and then slightly lower for the remainder of the experiment. Bile acid and biliary cholesterol specific activities increased more rapidly and reached a peak sooner after administration of isotopic FC in HDL than in LDL; this was observed previously (15).

Shown in Figs. 2 and 3 for the first time in humans are composite specific activities including bile acids and cholesterol in all major components of blood and bile. The peak specific activity of biliary cholesterol and bile acid was always less than that of plasma FC at the corresponding time. Plasma FC and biliary cholesterol specific activities merged after the initial 100-200 min, and thereafter remained nearly identical. Blood cell FC specific activity tended to increase more rapidly after administration of isotopic FC in HDL than in LDL. Equilibration of blood cell FC and plasma FC specific activities was reached by $400-600 \mathrm{~min}$ corresponding to the time when blood cell FC specific activity reached a peak. This suggests a precursor (plasma FC)-product (blood cell FC) relationship.

The specific activity of EC in plasma increased at a relatively slow rate for the initial $200 \mathrm{~min}$; then, either the rate of incline diminished considerably or the specific activity plateaued until it intersected plasma FC after $\sim 1,500 \mathrm{~min}$. The specific activities intersected at the plasma EC peak.

J.T. was first administered ${ }^{3} \mathrm{H}-\mathrm{FC}$ in VLDL/LDL $(d$ $\leq 1.062$ ) followed $25 \mathrm{~h}$ later by a second experiment in which HDL- ${ }^{3} \mathrm{H}-\mathrm{FC}$ was administered. The ${ }^{3} \mathrm{H}$ specific activity versus time patterns and interrelationships, shown in Fig. 3 (upper panel), were the same as those seen in I.D. and E.B. given the corresponding labeled lipoproteins (VLDL/LDL considered equivalent to $\mathrm{LDL}$ ). 
Table IV. Rate Constants and Delay Times Derived from Compartmental Analysis

\begin{tabular}{|c|c|c|c|c|c|c|c|c|c|c|}
\hline Subject & $\mathrm{L}(16,12)$ & $\mathrm{L}(10,12)$ & $L(4,12)$ & $L(12,4)$ & $\mathrm{L}(5,12)$ & $\mathrm{L}(12,5)$ & $\mathrm{L}(4,3)^{*}$ & $\mathrm{~L}(3,4)$ & $\mathrm{L}(5,3)^{\ddagger}$ & $\mathrm{L}(3,5)$ \\
\hline & \multicolumn{10}{|c|}{$\min ^{-1} \pm F S D$} \\
\hline I.D. & $0.00143 \pm 8 \%$ & $0.00015 \pm 9 \%$ & $0.00364 \pm 92 \%$ & $0.0330 \pm 21 \%$ & $0.00408 \pm 62 \%$ & $0.0019 \pm 36 \%$ & 0.00185 & $0.0147 \pm 16 \%$ & 0.00020 & $0.0004 \pm 107 \%$ \\
\hline E.B. & $0.00105 \pm 5 \%$ & $0.00010 \pm 5 \%$ & $0.00544 \pm 35 \%$ & $0.0293 \pm 11 \%$ & $0.00125 \pm 109 \%$ & $0.0029 \pm 17 \%$ & 0.00185 & $0.0156 \pm 11 \%$ & 0.00053 & $0.0014 \pm 29 \%$ \\
\hline J.T. & $0.00091 \pm 11 \%$ & $0.00040 \pm 11 \%$ & $0.00517 \pm 35 \%$ & $0.0316 \pm 16 \%$ & $0.00483 \pm 36 \%$ & $0.0028 \pm 22 \%$ & 0.00208 & $0.0243 \pm 10 \%$ & 0.00016 & $0.0003 \pm 88 \%$ \\
\hline R.T.I & $0.00156 \pm 16 \%$ & $0.00029 \pm 16 \%$ & $0.00532 \pm 43 \%$ & $0.0770 \pm 34 \%$ & $0.00536 \pm 40 \%$ & $0.0007 \pm 310 \%$ & 0.00087 & $0.0105 \pm 61 \%$ & 0.00112 & $0.0028 \pm 26 \%$ \\
\hline R.T.II & $0.00120 \pm 15 \%$ & $0.00018 \pm 15 \%$ & $0.00161 \pm 81 \%$ & $0.0387 \pm 18 \%$ & $0.00600 \pm 18 \%$ & $0.0011 \pm 48 \%$ & 0.00120 & $0.0177 \pm 12 \%$ & 0.00092 & $0.0026 \pm 12 \%$ \\
\hline
\end{tabular}

In these subjects not administered labeled mevalonic acid, $\mathrm{L}(11,23), \mathrm{L}(13,1), \mathrm{L}(12,1), t_{11}$ and $t_{13}$ could not be measured. $\mathrm{L}(13,1)$ and $\mathrm{L}(12,1)$ were fixed at 0.0535 and 0.9465 , respectively, calculated from the mean of corresponding values in Table VII normalized to $L(1,1)=1.00$.

${ }^{*} \mathrm{~L}(4,3)$ dependent on $\mathrm{L}(3,4) ; \mathrm{L}(4,3)=\mathrm{L}(3,4) \times \mathrm{M}(4) / \mathrm{M}(3) ; \mathrm{M}(3)$ and $\mathrm{M}(4)$ were determined experimentally (observed).

${ }^{\ddagger} \mathrm{L}(5,3)$ dependent on $\mathrm{L}(3,5) ; \mathrm{L}(5,3)=\mathrm{L}(3,5) \times \mathrm{M}(5) / \mathrm{M}(3) ; \mathrm{M}(3)$ and $\mathrm{M}(5)$ were determined experimentally (observed).

${ }^{8} \mathrm{~L}(8,18)=\mathrm{L}(18,8) \times 1.667$.

To avoid problems associated with use of albumin containing $\left[{ }^{14} \mathrm{C}\right]$ cholesterol in particulate form $(6,14)$ and to determine if albumin could be used to administer tracer-FC into blood in a more physiologic manner, J.T. was given albumin coupled by exchange with ${ }^{14} \mathrm{C}$-FC at the same times he was given the ${ }^{3} \mathrm{H}$-FC compounds. The observed ${ }^{14} \mathrm{C}$ specific activities are shown in Fig. 3 (lower panels). Qualitatively, the ${ }^{14} \mathrm{C}$ specific activity patterns in blood and bile components of J.T. were characteristic of those seen in all subjects administered isotopic FC in HDL. Also, the ${ }^{14} \mathrm{C}$ activities in J.T.I and J.T.II

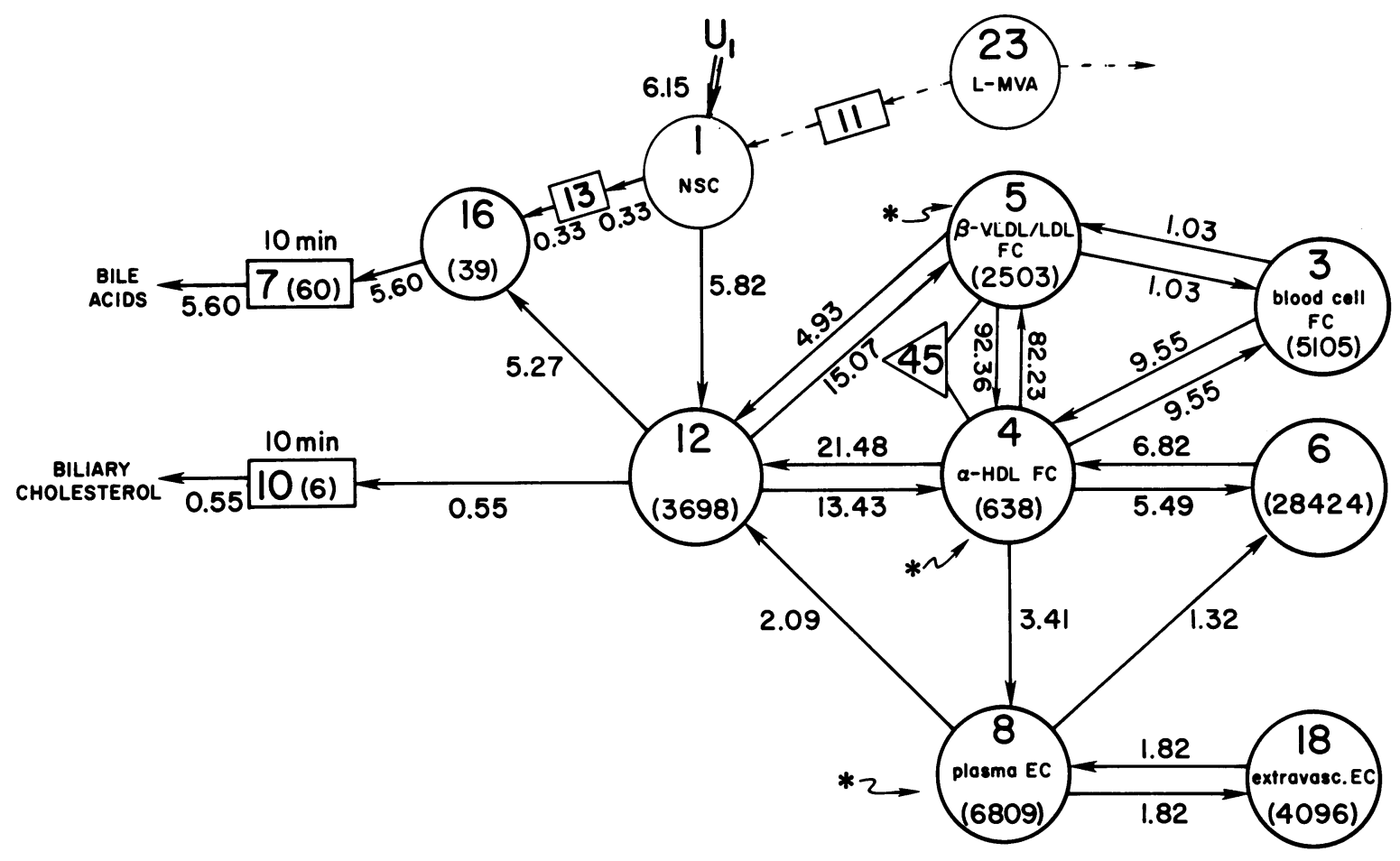

\section{BILE DUCTS}

Figure 4. Cholesterol model; used herein for subjects with total bile fistula in whom labeled FC in HDL and/or labeled FC in VLDL/LDL were administered and $\alpha$ and $\beta$ lipoproteins were rapidly isolated (I.D., E.B., J.T., R.T.I, and R.T.II). Parameter solutions for subject I.D. are shown. Circles represent standard compartments and rectangles represent delay compartments, each identified by the bold number in the compartment. The triangle represents a "summer" compartment, C(45), that contains whole plasma FC data (algebraic sum of $\alpha$-HDL FC and $\beta$-VLDL/LDL FC mass and radioactivity). Arrows represent transport pathways. Compartment size ( $M(n)$ in $\mu$ mol ), when it could be calculated, is in parentheses within the compartment. Transports, $R(m, n)$ in $\mu \mathrm{mol} / \mathrm{min}$, are adjacent to arrows. $U_{1}$ represents input (synthesis) of cholesterol in $\mu \mathrm{mol} / \mathrm{min}$ into compartment 1 . MVA; mevalonic acid; ${ }^{*}$ Labeled compound administered. Compartments 23,11 , and 1 are shown with thin lines and related transport pathways by dashed lines since they could not be defined in subjects not administered isotopic MVA. 


\begin{tabular}{|c|c|c|c|c|c|c|c|c|c|}
\hline$L(5,4)$ & $\mathrm{L}(4,5)$ & $\mathrm{L}(6,4)$ & $\mathrm{L}(4,6)$ & $\mathrm{L}(8,4)$ & $\mathrm{L}(12,8)$ & $\mathrm{L}(6,8)$ & $\mathrm{L}(18,8)^{\S}$ & $L(7,16)$ & $t_{7} ; t_{10}$ \\
\hline \multicolumn{9}{|c|}{$\min ^{-1} \pm F S D$} & $\min$ \\
\hline $0.1288 \pm 19 \%$ & $0.0368 \pm 14 \%$ & $0.0084 \pm 14 \%$ & $0.00024 \pm 15 \%$ & $0.0053 \pm 6 \%$ & $0.00031 \pm 31 \%$ & $0.00019 \pm 40 \%$ & $0.00027 \pm 33 \%$ & $0.142 \pm 11 \%$ & 10 \\
\hline $0.0941 \pm 11 \%$ & $0.0290 \pm 11 \%$ & $0.0096 \pm 5 \%$ & $0.00026 \pm 6 \%$ & $0.0058 \pm 5 \%$ & $0.00055 \pm 27 \%$ & $0.00001 \pm 550 \%$ & $0.00008 \pm 41 \%$ & $0.092 \pm 9 \%$ & 18 \\
\hline $0.1203 \pm 7 \%$ & $0.0224 \pm 8 \%$ & $0.0153 \pm 11 \%$ & $0.00045 \pm 27 \%$ & $0.0060 \pm 4 \%$ & $0.00021 \pm 56 \%$ & $0.00017 \pm 67 \%$ & $0.00010 \pm 98 \%$ & $0.100 \pm 14 \%$ & 10 \\
\hline $0.0382 \pm 76 \%$ & $0.0165 \pm 19 \%$ & $0.0252 \pm 25 \%$ & $0.00080 \pm 96 \%$ & $0.0069 \pm 5 \%$ & $0.00059 \pm 82 \%$ & $0.00001 \pm 400 \%$ & $0.00161 \pm 79 \%$ & $0.038 \pm 9 \%$ & 21 \\
\hline $0.0547 \pm 10 \%$ & $0.0164 \pm 9 \%$ & $0.0084 \pm 52 \%$ & $0.00015 \pm 263 \%$ & $0.0070 \pm 15 \%$ & $0.00003 \pm 295 \%$ & $0.00046 \pm 37 \%$ & $0.00163 \pm 103 \%$ & $0.066 \pm 11 \%$ & 28 \\
\hline
\end{tabular}

and the ${ }^{3} \mathrm{H}$ activities in J.T. II (given HDL- ${ }^{3} \mathrm{H}-\mathrm{FC}$ ) were nearly identical within each component at all times when expressed as fraction of dose.

Subject R.T.I was simultaneously administered VLDL- ${ }^{3} \mathrm{H}-$ $\mathrm{FC}$ and $\mathrm{LDL}-{ }^{14} \mathrm{C}-\mathrm{FC}$ to rigorously test the following observa- tions. In a previous study, a subject was also simultaneously administered VLDL- ${ }^{3} \mathrm{H}-\mathrm{FC}$ and LDL- ${ }^{14} \mathrm{C}-\mathrm{FC}$ but data collection was limited to $\alpha$ and $\beta$ lipoprotein samples (reference 7, subject 3 ). In this previous study, the fraction of ${ }^{3} \mathrm{H}-\mathrm{FC}$ dose observed in $\alpha$-FC was virtually identical to the fraction of ${ }^{14} \mathrm{C}$ -

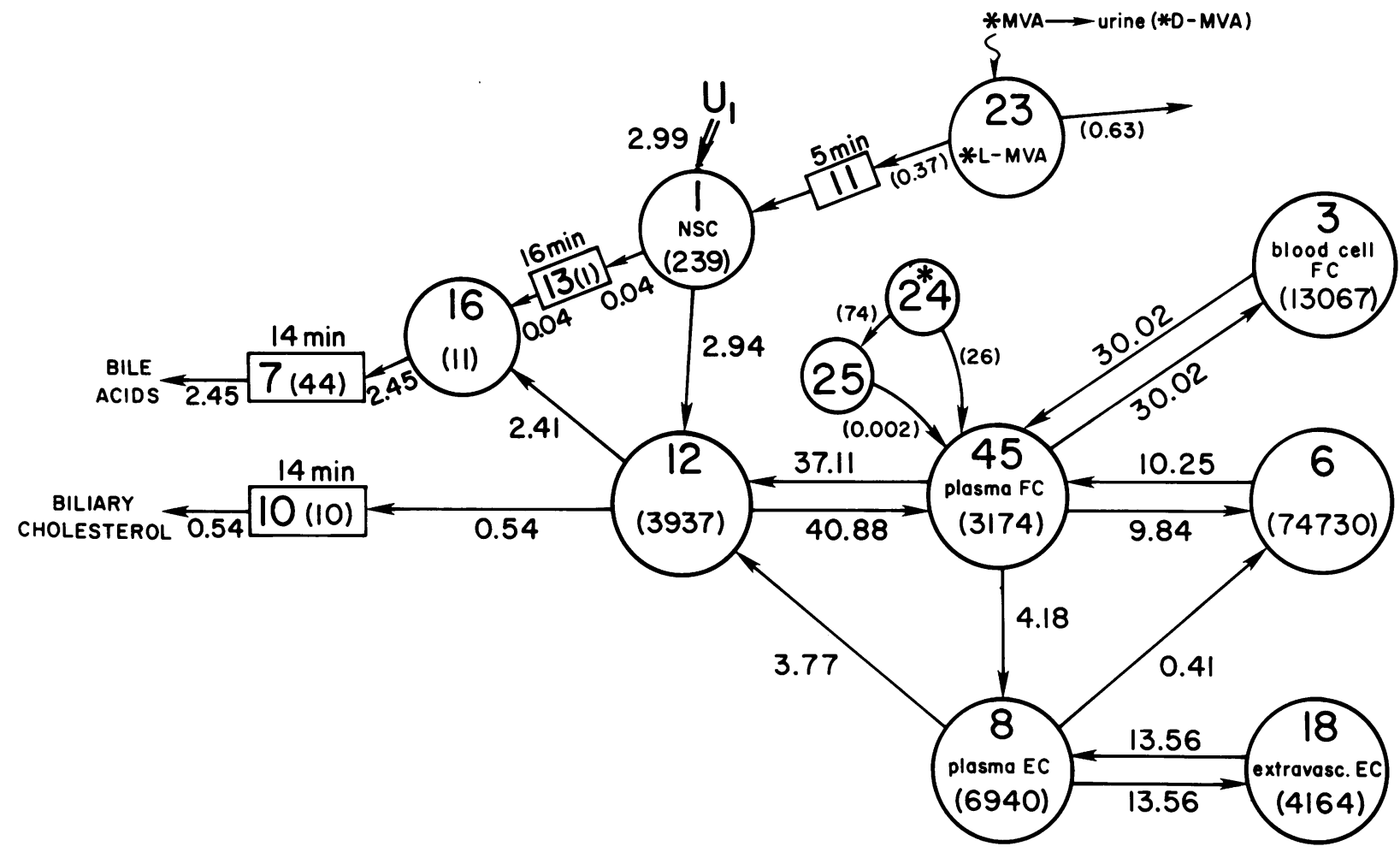

\section{BILE DUCTS}

PLASMA

TISSUE

Figure 5. Modified cholesterol model for the bile fistula subjects administered isotopic mevalonic acid ( $M V A)$ and albumin containing isotopic FC in particulate form. $\alpha$ and $\beta$ lipoproteins were not isolated. The only differences between this model and that shown in Fig. 4 are: $(a)$ the lumping of $C(4)$ and $C(5)$ from the Fig. 4 model into $C(45)$ and $(b)$ the presence of $C(24)$ and $C(25)$ to manage the isotopic FC administered in particulate form. Parameter solutions for subject E.H.I are shown. Compartment size $(M(n)$ in $\mu$ mol $)$ is in parentheses within the compartment. Transports, $\mathrm{R}(\mathrm{m}, \mathrm{n})$ in $\mu \mathrm{mol} / \mathrm{min}$, are adjacent to arrows. Number in parenthesis adjacent to an arrow represents the rate constant $(\mathrm{L}(\mathrm{m}, \mathrm{n}))$. Compartments $23,11,24$, and 25 represent isotope (tracer) only and contain no mass. $\mathrm{C}(23)$ and $\mathrm{C}(24)$ contain the total amount of injected tracers of L-MVA and FC, respectively. C (11) is a delay for incorporation of isotopic MVA into NSC. C(25) is particulate isotopic $\mathrm{FC}$ and $\mathrm{L}(25,24)$ represents the percent of injected isotopic $\mathrm{FC}$ in particulate form since $\mathrm{L}(24,24)$ was forced to equal $100 \mathrm{~min}^{-1}$. See text for discussion of isotopic FC in particulate form. Other symbols described in Fig. 4 legend. 
FC dose in $\alpha$-FC at each time. In addition, the fractions of ${ }^{3} \mathrm{H}$ dose in $\beta$-FC and of ${ }^{14} \mathrm{C}$ dose in $\beta$-FC were essentially identical. These observations suggested similarity of metabolism of FC in VLDL and LDL. For the new study in R.T.I, all components of blood and bile were isolated to search more rigorously for differences in LDL- and VLDL-FC metabolism. The ${ }^{3} \mathrm{H}$ and ${ }^{14} \mathrm{C}$ specific activities, expressed as fraction of dose per micromole, are shown in Table III. A difference between the fraction of ${ }^{3} \mathrm{H}$ dose and of ${ }^{14} \mathrm{C}$ dose within each component was tested for statistical significance using a nonparametric sign test. A chi square value of 6.75 was obtained for the difference between ${ }^{3} \mathrm{H}$ dose and ${ }^{14} \mathrm{C}$ dose in biliary cholesterol, significant at the 0.05 level for an average difference of only -0.002 . This is of doubtful physiologic significance especially since a difference between fraction of ${ }^{3} \mathrm{H}$ dose and of ${ }^{14} \mathrm{C}$ dose in each of the other five components did not approach statistical significance. The results strongly support similarity of metabolism of the FC in VLDL and LDL. Also, VLDL-FC and LDL-FC can be combined, as $\beta$-VLDL/LDL-FC without loss of sensitivity, for the purpose of kinetic analysis and modeling.

Subject R.T.II was administered VLDL- ${ }^{3} \mathrm{H}-\mathrm{FC}$; the specific activity versus time courses (not shown) observed in $\alpha$-FC, $\beta$-FC, plasma EC, blood cell FC, biliary cholesterol, and cholic acid had the same features as those shown in subjects who received isotopic FC in LDL, including I.D. (Fig. 2, lower-I and upper-II), E.B. and J.T. (Fig. 3, upper-I). R.T.II also received HDL- ${ }^{14} \mathrm{C}-\mathrm{FC}$; the specific activity versus time courses (not shown) of all components had the same features as other subjects administered isotopic FC in HDL or exchanged in albumin (J.T.I and J.T.II).

Kinetic analysis and modeling. The models (Figs. 4 and 5) were developed by subjecting the experimentally observed mass and specific activity ( $\mathrm{dpm} / \mu \mathrm{mol})$ data to multicompartmental analysis using the SAAM/CONSAM simulator on a VAX/8600 computer (Digital Equipment Co., Maynard, MA). Pool sizes of the individual plasma components (M(4), $M(5), M(45)$, and $M(8)$ ) and blood cells (M(3)) were determined from the observed plasma concentrations (Table I) and estimated plasma volume as $4.5 \%$ of $\mathrm{kg}$ body weight. During the modeling and iterative processes, the observed values for: $(a)$ plasma and blood cell pool sizes and $(b)$ biliary cholesterol and bile acid secretion rates were tightly constrained to stay within $5 \%$ of the experimentally observed values shown in Table I.

The only significant outputs of cholesterol from the body are via bile acid synthesis and biliary cholesterol secretion. Since each of these bile fistula subjects appeared to be in a steady state during the relatively brief experiments, the total cholesterol input $\left(U_{1}\right)$ in each subject was fixed at the sum of observed rates of bile acid secretion plus biliary cholesterol secretion.

The model was constrained by the simultaneous consideration of ${ }^{3} \mathrm{H}$ and ${ }^{14} \mathrm{C}$ specific activity data in each subject. This imposed rigid constraints on the topology of the model and narrowed the confidence limits on the final parameter values since the same kinetic parameters were required to fit both ${ }^{3} \mathrm{H}$ and ${ }^{14} \mathrm{C}$ radioactivity data obtained after administration of tracers in separate cholesterol pools. The multilabel (mevalonic acid, VLDL-FC, HDL-FC, and LDL-FC) approach afforded the opportunity to construct a model based on the transport of tracers between compartments that was consistent with the number of exponentials in the specific activity response of 
Table VI. Observed Pool Sizes and Pool Sizes Estimated Using Compartmental Analysis

\begin{tabular}{|c|c|c|c|c|c|c|c|c|c|c|}
\hline Subject & $\mathrm{M}(12)$ & $\mathrm{M}(3)^{*}$ & $\mathrm{M}(6)$ & $\mathrm{M}(4)^{*}$ & $\mathrm{M}(5)^{*}$ & $\mathrm{M}(8)^{*}$ & $\mathrm{M}(18)^{\ddagger}$ & $M(16)$ & $\mathbf{M}(7)$ & $M(10)$ \\
\hline & \multicolumn{10}{|c|}{$\mu m o l \pm F S D$} \\
\hline I.D. & $3,698 \pm 9 \%$ & 5,105 & $28,424 \pm 14 \%$ & 638 & 2,503 & 6,809 & 4,096 & $39 \pm 11 \%$ & $60 \pm 12 \%$ & $6 \pm 12 \%$ \\
\hline E.B. & $5,825 \pm 5 \%$ & 7,390 & $32,349 \pm 6 \%$ & 876 & 2,798 & 9,052 & 5,437 & $70 \pm 9 \%$ & $128 \pm 8 \%$ & $13 \pm 9 \%$ \\
\hline J.T. & $2,995 \pm 11 \%$ & 6,862 & $23,697 \pm 14 \%$ & 587 & 3,363 & 9,293 & 5,564 & $30 \pm 14 \%$ & $41 \pm 13 \%$ & $17 \pm 13 \%$ \\
\hline R.T.I & $4,111 \pm 15 \%$ & 6,042 & $15,901 \pm 70 \%$ & 502 & 2,393 & 5,727 & 3,436 & $180 \pm 9 \%$ & $168 \pm 21 \%$ & $30 \pm 20 \%$ \\
\hline R.T.II & $3,007 \pm 14 \%$ & 7,540 & $50,980 \pm 226 \%$ & 512 & 2,633 & 7,356 & 4,413 & $58 \pm 11 \%$ & $127 \pm 12 \%$ & $18 \pm 12 \%$ \\
\hline
\end{tabular}

$M(1)$ and $M(13)$ could not be estimated in these subjects since labeled mevalonic acid was not administered.

* Calculated from concentration (Table I) and plasma volume estimated as $4.5 \%$ of weight, then tightly constrained during the modeling.

${ }^{\ddagger} \mathrm{M}(18)=\mathrm{M}(8) / 1.667$; i.e., $\mathrm{M}(18)$ assumed to be $60 \%$ of $\mathrm{M}(8)$.

all observed compartments and could predict the specific activity response in the compartments where observations were not possible.

In E.H.I, $\alpha$ and $\beta$ lipoproteins were not isolated and tracers were not specifically injected into either $\alpha$-FC or $\beta$-FC compartments. Therefore, a modified model was used as shown in Fig. 5 in which there is a single whole plasma FC compartment, $\mathrm{C}(45)$. The primary model shown in Fig. 4 was used in experiments during which $\alpha$ and $\beta$ lipoprotein samples were isolated (I.D., E.B., J.T., and R.T.). The sum of C(4) and C(5), represented by $\mathrm{C}(45)$, was used to fit the whole plasma FC data also obtained. Regarding I.D. and E.B., although most of the observed FC data from plasma consisted of whole plasma FC specific activities, this approach allowed good identification and estimation of the parameters of $\mathrm{C}(4)$ and $\mathrm{C}(5)$ because: (a) labeled compounds were injected into $C(4)$ and $C(5)$ and (b) three to four $\alpha$ and $\beta$ lipoprotein samples, obtained within 90 min of administration of the labeled compounds, were sufficient to identify these parameters.

In I.D., E.B., and J.T., a second experiment (II) was carried out 1-3 d after the start of the first experiment (I). Because experiments I and II were at the same steady state, all data from experiment I including labeled material and all data from experiment II were combined with the second set of initial conditions introduced at the appropriate time and fit simultaneously. This allowed labeled material from experiment I to remain in the system during the fit of experiment II to obtain one final set of parameter solutions. In support of a steady state in I.D., E.B., and J.T., the bile fistula remained patent, bile flow was constant, and bile lipid secretion rates and blood cholesterol concentrations were unchanged from the start of experiment I through the end of experiment II. In contrast, R.T.I and R.T.II were fit separately since they were studied $35 \mathrm{~d}$ apart at markedly different steady states with regard to bile acid synthesis and biliary cholesterol secretion (Table I).

Development of the model. The final model is shown in Fig. 4. Except for the mevalonate portion, the model contains the minimal structure necessary to fit the data in I.D., E.B., J.T., and R.T., who were administered isotopic FC in lipoproteins along with a small amount of isotopic EC. The pathways designated by the thin dashed-lines, $\mathrm{C}(23), \mathrm{C}(1)$, delay 11 , and delay 13 are defined when isotopic mevalonic acid is administered. VLDL-FC and LDL-FC were modeled separately in the antecedent to this model (7). They are now combined in C(5) for reasons presented above and discussed previously (7).

The FC in blood cells $(\mathrm{C}(3)$, not in prior models) was assumed to exchange bidirectionally with FC in $\beta$-VLDL/LDL and in $\alpha$-HDL, compartments 5 and 4, respectively. The assumption of exchange without net transport means that $\mathrm{L}(4$, $3)$ and $L(3,4)$ were interdependent as were $L(5,3)$ and $L(3$, 5 ) since $M(3), M(4)$, and $M(5)$ were tightly constrained observations; therefore, $\mathrm{L}(3,4)$ and $\mathrm{L}(3,5)$ were adjustable and $\mathrm{L}(4,3)$ and $\mathrm{L}(5,3)$ were dependent during the iterative process. Transport (not only bidirectional exchange) of FC between $\alpha$-HDL and a rapidly turning over tissue pool (C(12), probably hepatic) was found previously (7). In the current model FC transport between $\mathrm{C}(12)$ and $\beta$-VLDL/LDL lipoproteins has been added since it improved the fit of several compartments, primarily of bile acids and biliary cholesterol.

$\alpha$-HDL-FC was the source of plasma EC, C(8), formed de novo in the model in Fig. 4. This pathway was based on previous modeling and a considerable body of data from other laboratories showing that HDL-FC and lecithin-cholesterol acyltransferase are the source of most plasma EC in man (16, 17). An EC exchange compartment, $C(18)$, was used to fit the slow change in specific activity of plasma EC after $300 \mathrm{~min}$ (Figs. 1-3). We found that $M(18)$ was $\sim 60 \%$ of $M(8)$ while modeling experiments with a duration of at least $2 \mathrm{~d}$. Other investigators have found that extravascular $\mathrm{ApoB}, \mathrm{Apo} \mathrm{A}_{1}$, and $\mathrm{ApoA}_{2}$ pools are $\sim 60 \%$ of the vascular pool sizes $(18,19)$. Therefore, we assumed $\mathrm{C}(18)$ is extravascular lipoprotein EC and have constrained $\mathrm{M}(18)$ to be $60 \%$ of $\mathrm{M}(8)$. Thus, $\mathrm{L}(8$, $18)$ and $\mathrm{L}(18,8)$ are interdependent; $\mathrm{L}(18,8)$ was allowed to adjust, and $L(8,18)$ was fixed equal to $L(18,8) \times 1.667$. The output of plasma $\mathrm{EC}$ was assumed to occur from $\mathrm{C}(8)$ to the tissue pools, $\mathrm{C}(12)$ and $\mathrm{C}(6)$, and both $\mathrm{L}(12,8)$ and $\mathrm{L}(6,8)$ were freely adjustable.

The bile acid and biliary cholesterol precursor pools and related transport pathways shown in Fig. 4 are simplified as compared with our previous report in which separate precursor pools were used (6). There were two reasons for the simplification. First, except for the longer delay before appearance of radioactivity in bile acids, the bile acid specific activities and biliary cholesterol specific activities were similar after administration of isotopic cholesterol to bile fistula subjects. Bile acid and biliary cholesterol specific activities were also similar starting $300 \mathrm{~min}$ after isotopic MVA administration. These similarities have occurred in every bile fistula subject suggesting a common precursor pool for biliary cholesterol and most newly synthesized bile acids. The marked difference between bile acid and biliary cholesterol specific activities during the period from 20 to $300 \mathrm{~min}$ (Fig. 1, upper panel) after isotopic mevalonic acid administration is addressed below. Second, examination of rate constants for separate bile acid and biliary cholesterol 
Table VII. Rate Constants and Delay Times Derived from Compartmental Analysis

\begin{tabular}{|c|c|c|c|c|c|c|c|c|c|}
\hline Subject & $\mathrm{L}(11,23)^{*}$ & $L(13,1)$ & $L(12,1)$ & $\mathrm{L}(16,12)$ & $L(10,12)$ & $\mathrm{L}(45,12)$ & $L(12,45)$ & $L(3,45)$ & $\llcorner(45,3)$ \\
\hline & & & & & & & & & $\min ^{-1} \pm F S D$ \\
\hline E.H.I & $0.37 \pm 3 \%$ & $0.00017 \pm 11 \%$ & $0.012 \pm 9 \%$ & $0.0006 \pm 6 \%$ & $0.00014 \pm 6 \%$ & $0.0104 \pm 6 \%$ & $0.0115 \pm 4 \%$ & $0.0093 \pm 8 \%$ & $0.0023 \pm 8 \%$ \\
\hline G.P. & $0.36 \pm 32 \%$ & $0.00086 \pm 19 \%$ & $0.033 \pm 17 \%$ & $0.0010 \pm 30 \%$ & $0.00043 \pm 30 \%$ & $0.0094 \pm 13 \%$ & $0.0140 \pm 18 \%$ & $0.0098 \pm 33 \%$ & $0.0049 \pm 33 \%$ \\
\hline P.C. & $0.42 \pm 6 \%$ & $0.00212 \pm 6 \%$ & $0.015 \pm 5 \%$ & $0.0008 \pm 4 \%$ & $0.00016 \pm 5 \%$ & $0.0093 \pm 7 \%$ & $0.0298 \pm 7 \%$ & $0.0049 \pm 72 \%$ & $0.0018 \pm 63 \%$ \\
\hline L.C. & $0.49 \pm 16 \%$ & $0.00063 \pm 13 \%$ & $0.027 \pm 9 \%$ & $0.0013 \pm 10 \%$ & $0.00017 \pm 10 \%$ & $0.0081 \pm 7 \%$ & $0.0150 \pm 10 \%$ & $0.0140 \pm 15 \%$ & $0.0052 \pm 16 \%$ \\
\hline T.T. & $0.40 \pm 5 \%$ & $0.00042 \pm 16 \%$ & $0.022 \pm 9 \%$ & $0.0009 \pm 4 \%$ & $0.00032 \pm 4 \%$ & $0.0066 \pm 5 \%$ & $0.0078 \pm 5 \%$ & $0.0095 \pm 8 \%$ & $0.0028 \pm 8 \%$ \\
\hline I.H. & $0.35 \pm 18 \%$ & $0.00603 \pm 34 \%$ & $0.075 \pm 24 \%$ & $0.0010 \pm 10 \%$ & $0.00025 \pm 11 \%$ & $0.0056 \pm 7 \%$ & $0.0061 \pm 9 \%$ & $0.0070 \pm 20 \%$ & $0.0031 \pm 19 \%$ \\
\hline G.A.I & $0.36 \pm 13 \%$ & $0.00372 \pm 18 \%$ & $0.036 \pm 16 \%$ & $0.0013 \pm 5 \%$ & $0.00032 \pm 5 \%$ & $0.0066 \pm 7 \%$ & $0.0091 \pm 6 \%$ & $0.0101 \pm 12 \%$ & $0.0040 \pm 13 \%$ \\
\hline
\end{tabular}

* Plasma mevalonic acid turnover $[\mathrm{L}(23,23)]$ was fixed at $1.0 \mathrm{~min}^{-1}$ in all subjects $[\mathrm{L}(0,23)=1-\mathrm{L}(11,23)]$.

${ }^{\ddagger} \mathrm{L}(8,18)=\mathrm{L}(18,8) \times 1.667$.

${ }^{8} \mathrm{~L}(24,24)=100$ when intravenous particulate ${ }^{3} \mathrm{H}$ - or ${ }^{14} \mathrm{C}$-FC administered $[\mathrm{L}(45,24)=100-\mathrm{L}(25,24)]$.

precursor pools, called $\mathrm{C}(2)$ and $\mathrm{C}(3)$, respectively, in the previous report, revealed they were nearly identical (Table $\mathrm{V}$ in reference 6 ). Therefore, we propose the simplified model (Fig. 4) containing a common precursor pool, C(12), for bile acid synthesis and biliary cholesterol secretion. We have retained pathways from the previous model for newly synthesized cholesterol (NSC) transport directly into bile acids, now called $\mathrm{L}(13,1)$. This direct input of NSC accounts for the difference between bile acid and biliary cholesterol specific activities seen between 20 and 300 min after isotopic mevalonic acid administration.

The delayed appearance of radioactivity in biliary cholesterol was due to transit time through the biliary tract, delay 10 in Fig. 4. An identical portion of the time delay for bile acids was fixed to equal the delay for biliary cholesterol $\left(t_{7}=t_{10}\right)$. An additional delay-like feature was necessary for bile acids and the time required for passage through $\mathrm{C}(16)$ was used. $\mathrm{C}(16)$ probably represents intermediates in the bile acid synthetic pathway.

The model shown in Fig. 5 was modified from Fig. 4 and used to analyze the data in E.H.I and six subjects previously studied with isotopic FC in particulate form and isotopic mevalonic acid (6). Since a comprehensive model was not developed then, forcing functions had been used to simulate the plasma FC and EC specific activities and the information obtained from the 6 prior experiments was of limited scope (6). For the present analysis, $M(3)$ was estimated for the six old studies from hematocrit and plasma volume and from mean blood cell FC concentration of the new studies in this report. Radioactivity was not measured in the blood cells of E.H.I but mass was measured in three samples (Table I). M(3) was loosely constrained $( \pm 30 \%)$ to the estimated value during analysis of all seven experiments with the modified model in Fig. 5.

In the modified model, Fig. 5, C(24) represents total injected tracer FC of which a major portion is in particulate form. $\mathrm{L}(24,24)$ was fixed at $100.0 \mathrm{~min}^{-1}$ to instantaneously distribute the injected tracer. $\mathrm{L}(45,24)$ was dependent $(\mathrm{L}(45,24)$ $=100-\mathrm{L}(25,24))$ and $\mathrm{L}(25,24)$ was adjustable. Thus, all tracer injected into $\mathrm{C}(24)$ was instantly partitioned between $\mathrm{C}(25)$, particulate tracer FC, and C(45), plasma FC.

E.H.I was administered $\left[{ }^{3} \mathrm{H}\right]$ mevalonic acid simultaneously with the particulate ${ }^{14} \mathrm{C}$-FC. In Fig. 5, the mevalonate tracer pool $(\mathrm{C}(23))$, delay 11 , and NSC $(\mathrm{C}(1))$ are adopted from previous publications $(6,7)$. Delay 13 is new and was necessary to postpone appearance of radioactivity from NSC in secreted bile acids.

Model parameter solutions. The rate constants $(\mathrm{L}(\mathrm{m}, \mathrm{n}))$ and delay times $\left(t_{n}\right)$ for subjects I.D., E.B., J.T., and R.T. are shown in Table IV. Rate constants among subjects varied to an extreme degree (more than sevenfold) only for pathways that had comparatively low values; for example, $L(3,5)$ and $L(6$, 8) varied over a wide range and had high fractional standard deviation (FSD) when compared to $\mathrm{L}(3,4)$ and $\mathrm{L}(12,8)$, respectively. As expected in brief experiments ( $<1,000 \mathrm{~min}$ ), the solutions for pathways from compartments with slow turnover were highly variable and poorly defined (high FSD) in subjects R.T.I and R.T.II; examples were $L(4,6)$, L( 12,8$)$, $\mathrm{L}(6,8)$, and $\mathrm{L}(18,8)$. The value of administering label into two compartments is shown in R.T.I in whom both labels were administered into $C(5) ; L(12,5), L(3,4)$, and $L(5,4)$ varied widely from the other subjects and were poorly defined.

Transport rates $(\mu \mathrm{mol} / \mathrm{min})$ for subjects I.D., E.B., J.T., and R.T. are shown in Table V. The high rate of FC transport between $\alpha$-HDL and $\beta$-VLDL/LDL $(\mathrm{R}(5,4)$ and $\mathrm{R}(4,5))$ was expected (7). A striking new result was the high rate of FC transport between $\alpha$-HDL and the putative liver $(\mathrm{C}(12))$, blood cell $(\mathrm{C}(3))$, and other tissue $(\mathrm{C}(6))$ pools relative to the transport between $\beta$-VLDL/LDL and the same pools. This central role of HDL occurred even though the concentration of HDL FC was $\sim 25 \%$ of VLDL/LDL FC. There was net FC efflux to HDL from tissue $C(6)$, the magnitude of which depended on the amount of plasma EC that entered $C(6)$. A portion of the FC transport between $\alpha$-HDL and C(12) was undoubtedly due to bidirectional exchange, but there was net FC transport of 3-17 $\mu \mathrm{mol} / \mathrm{min}$ to $\mathrm{C}(12)$ from HDL in four of five experiments. Transport of plasma $\mathrm{EC}$ to $\mathrm{C}(12)$ was greater than to $C(6)$ in four of five experiments; in the exception (R.T.II), this difference was very poorly estimated because of the brief duration of the experiment.

Pool sizes in units of $\mu \mathrm{mol}$ are shown in Table VI. As expected, $M(6)$ was the largest pool but in the brief experiments in R.T., M(6) varied from the values for I.D., E.B., and J.T., and was less well defined (high FSD). M(12) was well defined even in brief experiments because of its rapid turnover. M(12) was much larger than the mass of separate bile acid and biliary cholesterol precursor pools estimated with a previous model in which many FC transport pathways were not identified (6).

Table VII shows the rate constants and delay times for EHI 


\begin{tabular}{|c|c|c|c|c|c|c|c|c|c|c|c|}
\hline $\mathrm{L}(6,45)$ & $\mathrm{L}(45,6)$ & $\mathrm{L}(8,45)$ & $\mathrm{L}(12,8)$ & $\mathrm{L}(6,8)$ & $\mathrm{L}(18,8)^{\ddagger}$ & $\mathrm{L}(25,24)^{8}$ & $\mathrm{~L}(45,25)$ & $L(7,16)$ & $t_{11}$ & $t_{13}$ & $\begin{array}{l}7 \\
t_{10}\end{array}$ \\
\hline & & & & & & & & & & $\min$ & \\
\hline $0.0030 \pm 5 \%$ & $0.00014 \pm 5 \%$ & $0.00129 \pm 4 \%$ & $0.00056 \pm 4 \%$ & $0.00006 \pm 250 \%$ & $0.00203 \pm 33 \%$ & $74 \pm 7 \%$ & $0.00198 \pm 5 \%$ & $0.220 \pm 300 \%$ & 5 & 16 & 14 \\
\hline $0.0053 \pm 81 \%$ & $0.00098 \pm 69 \%$ & $0.00154 \pm 9 \%$ & $0.00023 \pm 290 \%$ & $0.00053 \pm 130 \%$ & $0.00130 \pm 62 \%$ & $88 \pm 18 \%$ & $0.00167 \pm 18 \%$ & $0.040 \pm 20 \%$ & 9 & 10 & 17 \\
\hline $0.0095 \pm 23 \%$ & $0.00095 \pm 36 \%$ & $0.00213 \pm 8 \%$ & $0.00093 \pm 8 \%$ & $0.00009 \pm 200 \%$ & $0.00200 \pm 52 \%$ & $51 \pm 9 \%$ & $0.00387 \pm 13 \%$ & $0.044 \pm 7 \%$ & 3 & 14 & 8 \\
\hline $0.0064 \pm 26 \%$ & $0.00058 \pm 22 \%$ & $0.00178 \pm 6 \%$ & $0.00061 \pm 24 \%$ & $0.00005 \pm 200 \%$ & $0.00020 \pm 51 \%$ & $90 \pm 12 \%$ & $0.00022 \pm 13 \%$ & $0.074 \pm 14 \%$ & 4 & 15 & 11 \\
\hline $0.0012 \pm 22 \%$ & $0.00010 \pm 9 \%$ & $0.00285 \pm 7 \%$ & $0.00078 \pm 9 \%$ & $0.00018 \pm 53 \%$ & $0.00096 \pm 38 \%$ & $92 \pm 13 \%$ & $0.00149 \pm 4 \%$ & $0.051 \pm 14 \%$ & 7 & 17 & 13 \\
\hline $0.0012 \pm 57 \%$ & $0.00008 \pm 44 \%$ & $0.00172 \pm 8 \%$ & $0.00079 \pm 29 \%$ & $0.00001 \pm 200 \%$ & $0.00180 \pm 45 \%$ & - & - & $0.043 \pm 40 \%$ & 5 & 15 & 20 \\
\hline $0.0014 \pm 21 \%$ & $0.00074 \pm 11 \%$ & $0.00204 \pm 6 \%$ & $0.00048 \pm 10 \%$ & $0.00040 \pm 40 \%$ & $0.00084 \pm 34 \%$ & - & - & $0.039 \pm 27 \%$ & 7 & 15 & 26 \\
\hline
\end{tabular}

and for the six previous experiments reanalyzed with the new model in Fig. 5. $\mathrm{L}(11,23)$ is the fraction of tracer mevalonic acid converted to cholesterol; the range was $35-49 \%$. $\mathrm{L}(13,1)$ and $\mathrm{L}(12,1)$ comprised a mean of 5.35 and $94.65 \%$, respectively, of $\mathrm{L}(1,1)$. The mean $\mathrm{L}(1,1)$ was $0.0334 \mathrm{~min}^{-1}$ equivalent to a $t_{1 / 2}$ of $21 \mathrm{~min}$ for NSC. Most of the rate constants in Table VII have either corresponding or equivalent counterparts in Table IV; they are remarkably similar among all 12 experiments in spite of use of a variety of labeled compounds. Equivalent rate constants in Tables VII and IV included: $(a)$ $\mathrm{L}(45,12)$ and $\mathrm{L}(4,12)+\mathrm{L}(5,12),(b) \mathrm{L}(45,3)$ and $\mathrm{L}(4,3)$ $+\mathrm{L}(5,3)$, and $(c) \mathrm{L}(45,6)$ and $\mathrm{L}(4,6)$. As in Table IV, $\mathrm{L}(12$, 8) was greater than $\mathrm{L}(6,8)$ with a single exception, subject G.P. in whom the experiment lasted $<1,000 \mathrm{~min}$. The solution for $\mathrm{L}(25,24)$ shows that $51-92 \%$ of the FC tracer was administered in particulate form.

Transport rates for subject E.H.I and the six reanalyzed experiments are shown in Table VIII. Compared with transports in Table $\mathrm{V}$, the corresponding and equivalent transport rates in Table VIII are remarkably similar. FC was transported most rapidly between plasma and (in descending order) the liver (C(12)), blood cells, and other tissues. Cholesterol ester synthesis, $R(8,4)$ and $R(8,45)$, was within a narrow range, $3.41-7.16 \mu \mathrm{mol} / \mathrm{min}$.

Pool sizes for E.H.I and from reanalysis of the six previous experiments are shown in Table IX. The NSC pool size, $M(1)$, was only $\sim 4 \%$ of the exchangeable hepatic FC pool, M(12). The adjustable pool sizes were well defined (low FSD) with rare exception.

$M(12)$, the size of the putative hepatocyte cholesterol pool available for bile acid synthesis was directly related to $R(0,7)$, the rate of bile acid synthesis. The relationship and regression analysis are shown in Fig. 6, for which each subject's M(12) and $R(0,7)$ were normalized to a body weight of $70 \mathrm{~kg}$. Sensitivity testing (20) revealed that the relationship was not due to dependence of $M(12)$ on $U_{1}$, but to FC transport between $\mathrm{C}(12)$ and plasma. Testing was done by changing $U_{1}$ over a sixfold range with bile acid synthesis tightly constrained to the experimentally observed rate; $M(12)$ changed $<10 \%$.

\section{Discussion}

The model shown in Fig. 4 is the first in humans which has comprehensively identified and quantitated cholesterol trans- port between all major components of blood, several tissues, and bile. The pools and transports identified in these experiments, which ranged in duration from $8 \mathrm{~h}$ to $6 \mathrm{~d}$ in humans with chronic bile fistula, most likely represent cholesterol within the rapidly miscible pool characterized by Goodman and Samuel and their co-workers $(5,21)$. In support, the sum of all pool sizes normalized to $70 \mathrm{~kg}$ body wt was $55,242 \mu \mathrm{mol}$ $(21.4 \mathrm{~g})$, averaged from the 12 measurements in 11 bile fistula subjects. Samuel and Perl estimated a rapidly miscible pool size of $25.3 \mathrm{~g}$ in two normal subjects and Smith et al. estimated a pool of $25.9 \mathrm{~g}$ in eight normals with intact enterohepatic circulation $(21,22)$.

The model shown in Fig. 4 and as modified in Fig. 5 identifies the major cholesterol compartments and transports in the liver. Since hepatocytes are the major site of cholesterol synthesis in the whole animal, it was essential to define trafficking and/or sorting of hepatic NSC. Sorting has been difficult to

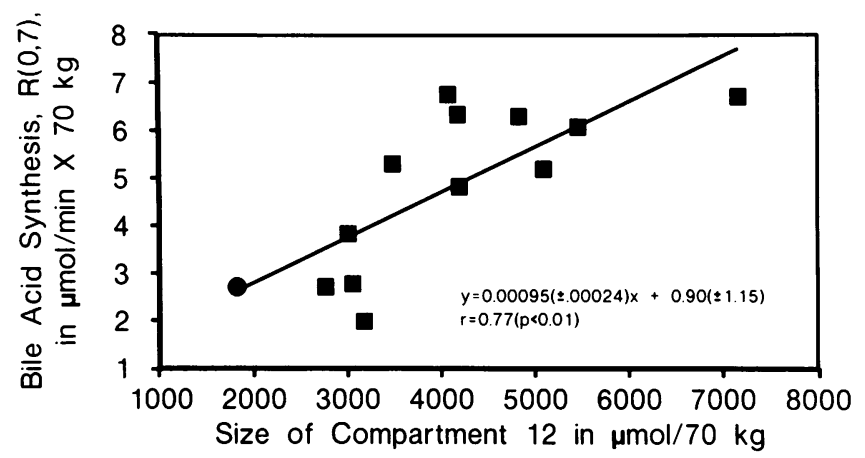

Figure 6. Relationship between the size of compartment 12, M(12), and the rate of bile acid synthesis, $R(0,7)$, in bile fistula subjects. The values shown here for $M(12)$ and $R(0,7)$ have been normalized to $70 \mathrm{~kg}$ body wt. Compartment 12 in the model (Figs. 4 and 5) is hepatic cholesterol that exchanges rapidly with plasma lipoproteins and also serves as precursor for biliary cholesterol and most newly synthesized bile acids. Shown are the data from all 13 bile fistula subjects studied to date by the investigators; 12 subjects ( $\square$ ) were described in this report and in part in reference 6 , and 1 subject (S.W.; -) was studied with a different design using esterified ${ }^{3} \mathrm{H}$ - and free ${ }^{14} \mathrm{C}$-cholesterol in $\mathrm{HDL}$ and analyzed using the model in Fig. 4. The linear regression results \pm SE for the slope and $y$ intercept are shown; $t=3.98, P<0.005$. The $y$ intercept $(0.90)$ was not significantly different from 0. Without S.W., $y=0.00096( \pm .00029) \times+0.85$ $( \pm 1.21) ; r=0.73(P<0.01) ; t=3.38, P<0.01$. 


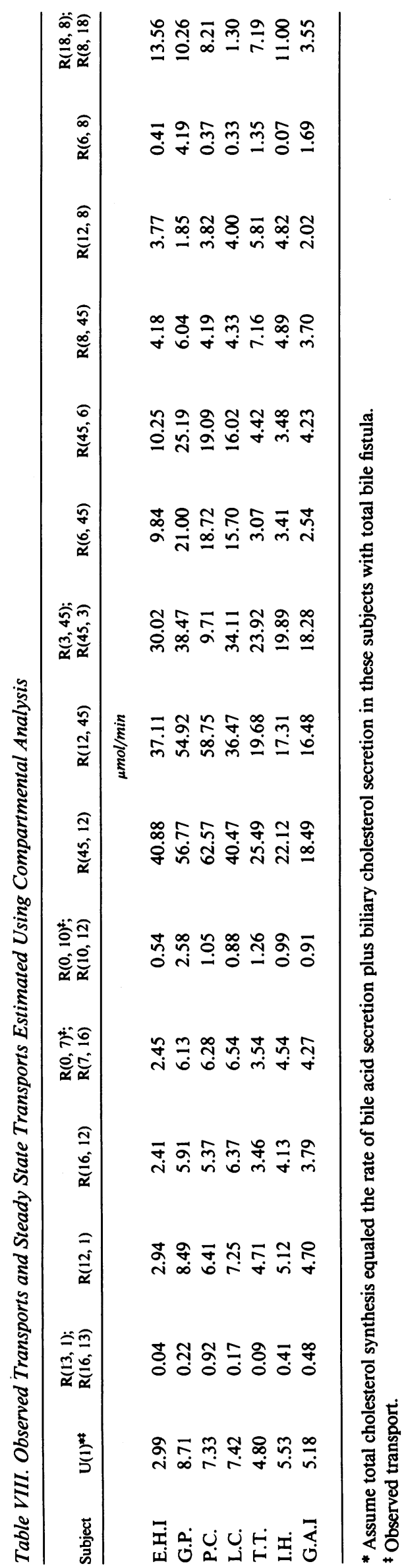

study because, unlike newly synthesized protein, NSC has neither an identifiable intracellular location nor a marker such as signal peptide or propiece. Parameters of NSC were quantitated using isotopes to simultaneously label two cholesterol pools: $(a)$ preformed exchangeable cholesterol with isotopic FC introduced in blood and $(b)$ NSC with isotopic mevalonic acid. With this design, the isotopic FC accurately defined the exchangeable cholesterol pool in the liver, $\mathrm{C}(12)$, which then allowed accurate definition of size and rate constants of NSC (C(1)) by the isotopic mevalonic acid. The $t_{1 / 2}$ of NSC was 21 min and the average size of $\mathrm{C}(1)$ was $219 \mu \mathrm{mol} / 70 \mathrm{~kg}$. Thus, the pool of NSC represents $<3 \%$ of total hepatic free cholesterol assuming the latter value is $\sim 7,500 \mu \mathrm{mol}$ (see below). Using entirely different methods, Lange reported similar values: NSC constituted $1 \%$ of fibroblast free cholesterol, had a $t_{1 / 2}$ of 10-60 min in fibroblasts, and had a $t_{1 / 2}$ of $20-30 \mathrm{~min}$ in Leydig tumor cells (23).

We found that $<6 \%$ of newly synthesized cholesterol molecules were used directly for bile acid synthesis and these passed through a 15 -min delay; $>94 \%$ of NSC entered the exchangeable hepatic pool, C (12), and most of this cholesterol entered plasma. The enzyme cholesterol $7 \alpha$-hydroxylase is located in the endoplasmic reticulum. If the final step of cholesterol synthesis was also located in the endoplasmic reticulum, it might be anticipated that $>6 \%$ would be used by cholesterol $7 \alpha$-hydroxylase in these subjects with maximally stimulated cholesterol and bile acid synthesis. Investigators have found that the final step in cholesterol synthesis occurs distant from endoplasmic reticulum, or that NSC is segregated in vesicles for transport to plasma membrane $(24,25)$. Our data support the latter possibilities.

Our results in conjunction with those of other investigators suggest that most of $\mathrm{C}(12)$ is located in hepatocytes of these bile fistula subjects. ( $a$ ) A compartment with the size and rate constants of $\mathrm{C}(12)$ was necessary to fit the plasma FC specific activity and mass data and to fit the biliary cholesterol, cholic acid, and chenodeoxycholic acid specific activity data. (b) The normal liver $(1,500 \mathrm{~g} / 70 \mathrm{~kg}$ adult $)$ contains $\sim 5 \mu \mathrm{mol} \mathrm{FC/g}$ wet wt or a total of $\sim 7,500 \mu \mathrm{mol}$ FC. Compartment 12 averaged $4,211 \mu \mathrm{mol} / 70 \mathrm{~kg}$, well within this upper limit of 7,500 $\mu$ mol. The latter value includes FC in nonparenchymal cells. If nonparenchymal cell FC exchanged slowly with plasma and comprised part of $C(6)$, then $C(12)$ could possibly comprise the vast majority of hepatocyte FC. This possibility is compatible with the findings of Johnson et al. in a hepatoma cell line; nearly $100 \%$ of the FC in Fu5AH cells was in rapid equilibrium with HDL in the media (26).

Cholesterol is present in all membranes of the hepatocyte with the largest portion, $\sim 80 \%$, in plasma membrane (27). Bile acid synthesis starts from cholesterol in the endoplasmic reticulum. In light of the kinetics suggesting that $C(12)$, with a $t_{1 / 2}$ of $72 \mathrm{~min}$, comprises the majority of hepatocyte cholesterol and substrate for bile acid synthesis, there must be very rapid equilibration of FC between plasma membrane and certain interior membranes; the $t_{1 / 2}$ for this equilibration between membranes must be $<15$ min or the FC in interior membranes could have been detected by the kinetic analysis. Availability of FC specifically in endoplasmic reticulum is, therefore, not rate limiting for bile acid synthesis in the intact cell. The direct relationship with $M(12)$ (Fig. 6) does suggest that bile acid synthetic rate, $R(0,7)$, is regulated in part by the amount of FC in plasma membrane and rapidly exchanging 
Table IX. Observed Pool Sizes and Pool Sizes Estimated Using Compartmental Analysis

\begin{tabular}{|c|c|c|c|c|c|c|c|c|c|c|c|}
\hline Subject & $\mathbf{M}(1)$ & $\mathrm{M}(12)$ & $\mathrm{M}(3)^{*}$ & $\mathrm{M}(6)$ & $M(45)^{\ddagger}$ & $\mathbf{M}(8)^{\ddagger}$ & $\mathrm{M}(18)^{5}$ & $\mathrm{M}(16)$ & $\mathbf{M}(13)$ & $\mathbf{M}(7)$ & $\mathbf{M}(10)$ \\
\hline & \multicolumn{11}{|c|}{$\mu \mathrm{mol} \pm F S D$} \\
\hline E.H.I & $239 \pm 8 \%$ & $3,937 \pm 6 \%$ & $13,067 \pm 3 \%(9,420)$ & $74,730 \pm 4 \%$ & 3,174 & 6,940 & 4,164 & $11 \pm 350 \%$ & $1 \pm 52 \%$ & $44 \pm 12 \%$ & $10 \pm 13 \%$ \\
\hline G.P. & $257 \pm 15 \%$ & $6,025 \pm 29 \%$ & $7,832 \pm 6 \%(7,942)$ & $25,707 \pm 54 \%$ & 3,919 & 7,918 & 4,749 & $152 \pm 20 \%$ & $2 \pm 99 \%$ & $150 \pm 29 \%$ & $63 \pm 29 \%$ \\
\hline P.C. & $433 \pm 5 \%$ & $6,710 \pm 4 \%$ & $5,368 \pm 5 \%(5,394)$ & $20,097 \pm 15 \%$ & 1,976 & 4,107 & 2,464 & $144 \pm 7 \%$ & $13 \pm 16 \%$ & $61 \pm 10 \%$ & $10 \pm 10 \%$ \\
\hline L.C. & $270 \pm 9 \%$ & $5,025 \pm 10 \%$ & $6,567 \pm 5 \%(6,981)$ & $27,520 \pm 19 \%$ & 2,401 & 6,508 & 3,902 & $89 \pm 14 \%$ & $3 \pm 20 \%$ & $107 \pm 12 \%$ & $14 \pm 12 \%$ \\
\hline T.T. & $215 \pm 9 \%$ & $3,886 \pm 4 \%$ & $8,594 \pm 5 \%(8,701)$ & $43,392 \pm 9 \%$ & 2,517 & 7,592 & 4,551 & $69 \pm 15 \%$ & $2 \pm 14 \%$ & $68 \pm 13 \%$ & $24 \pm 13 \%$ \\
\hline I.H. & $68 \pm 34 \%$ & $3,955 \pm 11 \%$ & $6,471 \pm 5 \%(6,328)$ & $42,264 \pm 51 \%$ & 2,839 & 6,120 & 3,672 & $105 \pm 39 \%$ & $7 \pm 14 \%$ & $129 \pm 14 \%$ & $28 \pm 14 \%$ \\
\hline G.A.I & $129 \pm 26 \%$ & $2,809 \pm 4 \%$ & $4,565 \pm 5 \%(4,848)$ & $5,715 \pm 12 \%$ & 1,836 & 4,239 & 2,540 & $110 \pm 27 \%$ & $8 \pm 9 \%$ & $183 \pm 9 \%$ & $40 \pm 10 \%$ \\
\hline
\end{tabular}

${ }^{*}$ Kinetic solution \pm FSD (initial estimate); initial estimate determined from Table I for E.H.I (Hct $=44 \%, 307 \mu \mathrm{mol} \mathrm{cholesterol} / \mathrm{dl}$ blood cells) and estimated as $211 \mu \mathrm{mol} \mathrm{FC} / \mathrm{dl}$ plasma in G.P., P.C., L.C., T.T., I.H., and G.A.I; Hct $=35-41 \%$. Initial estimate for M(3) loosely constrained $( \pm 30 \%)$ during the iterative process.

${ }^{\ddagger}$ Calculated from concentration (Table I) and plasma volume estimated as $4.5 \%$ of kg body wt, then tightly constrained ( $\pm 5 \%$ ) during the modeling and iterative process.

${ }^{\S} \mathrm{M}(18)=\mathrm{M}(8) / 1.667$; i.e., $\mathrm{M}(18)$ assumed to be $60 \%$ of $\mathrm{M}(8)$.

interior membranes. It seems unlikely that $\mathrm{C}(16)$ represents microsomal FC available for bile acid synthesis since $\mathrm{M}(16)$ was very small, had features of a delay, was all destined for bile acids, and was only weakly related to bile acid synthetic rate; $\mathrm{C}(16)$ probably represents intermediates in the synthetic pathway.

We found a direct correlation between the bile acid precursor pool size, $\mathrm{M}(12)$, and the rate of bile acid synthesis, $R(0,7)$. The analysis shed some light on the mechanism of this interrelationship. The rate of bile acid synthesis is regulated by the amount and activity of cholesterol $7 \alpha$-hydroxylase and possibly by the amount of available cholesterol substrate (28). In rats, regulation by availability of microsomal cholesterol substrate for $7 \alpha$-hydroxylase has not been supported by Bjorkhem et al. who found excess substrate (29). Regulation could be different in humans, or cholesterol in $\mathrm{C}(12)$ could regulate the amount of $7 \alpha$-hydroxylase at the gene transcription level in both species (30). The data in this report shows that in humans the amount of available cholesterol substrate, $M(12)$, is excessive supporting the latter means of regulation of bile acid synthesis by hepatic cholesterol.

The reason(s) that FC in the liver exchanges extensively and rapidly with plasma HDL but not LDL or VLDL is unknown. Intimate contact between plasma lipoproteins and hepatocyte via the space of Disse offers a partial explanation. However, blood cells are even more intimately exposed to plasma and they exchange FC several-fold slower than does the liver. The unique features of hepatocyte plasma membranes could include HDL receptors, phospholipid composition, or the proximity of hepatic lipase.

The findings support a central role for HDL in FC exchange/transport and agree with evidence from Francone et al. that cell derived FC appears first in HDL (7,31). All tissues identifiable with our model, $\mathrm{C}(12), \mathrm{C}(3)$, and $\mathrm{C}(6)$, exchanged FC with HDL much more extensively than with VLDL/LDL. This preferential exchange with HDL FC occurred even though the mass of HDL FC was only $25 \%$ of VLDL/LDL FC.

In 10 of the 12 experiments in these bile fistula subjects, the major pathway for plasma EC output was to the liver, $\mathrm{C}(12)$. In the two exceptions, plasma EC output was preferentially to nonhepatic tissue, $C(6)$. However, both of these exceptions were studied for a brief duration $(<1,000 \mathrm{~min})$ and the EC pathways were poorly defined because of this. Therefore, we conclude that the major site of plasma EC uptake is the liver. This is compatible with knowledge that, quantitatively in humans, the liver is the prevailing organ with regard to LDL receptor number and LDL catabolism.

\section{Acknowledgments}

The skillful secretarial assistance of Suellen Brogan is gratefully acknowledged. The advice and assistance of Drs. Leon Swell, Z. Reno Vlahcevic, and Mones Berman at various stages of the work are greatly valued.

This work was supported by U.S. Public Health Service (National Institutes of Health) grants AM25920, PO1-DK38030, and RR00065 (General Clinical Research Center), and the Grants-in-Aid Program of Virginia Commonwealth University.

\section{References}

1. Hellman, L., R. S. Rosenfeld, M. L. Eidinoff, D. K. Fukushima, T. F. Gallagher, C.-I. Wang, and D. Adlersberg. 1955. Isotopic studies of plasma cholesterol of endogenous and exogenous origins. J. Clin. Invest. 34:48-60.

2. Gould, R. G., G. V. LeRoy, G. T. Okita, J. J. Kabara, P. Keegan, and D. M. Bergenstal. 1955. The use of ${ }^{14} \mathrm{C}$-labeled acetate to study cholesterol metabolism in man. J. Lab. Clin. Med. 46:372-384.

3. Field, H., L. Swell, P. E. Schools, and C. R. Treadwell. 1960. Dynamic aspects of cholesterol metabolism in different areas of the aorta and other tissues in man and their relationship to atherosclerosis. Circulation. XXII:547-558.

4. Kurland, G. S., J. L. Lucas and A. S. Freedberg. 1961. The metabolism of intravenously infused ${ }^{14} \mathrm{C}$-labeled cholesterol in euthyroidism and myxedema. $J$. Lab. Clin. Med. 57:574-585.

5. Goodman, D. S., R. P. Noble, and R. B. Dell. 1973. Three-pool model of the long-term turnover of plasma cholesterol in man. J. Lipid Res. 14:178-188.

6. Schwartz, C. C., M. Berman, Z. R. Vlahcevic, L. G. Halloran, D. H. Gregory, and L. Swell. 1978. Multicompartmental analysis of cholesterol metabolism in man: characterization of the hepatic bile acid and biliary cholesterol precursor sites. J. Clin. Invest. 61:408-423.

7. Schwartz, C. C., Z. R. Vlahcevic, M. Berman, J. G. Meadows, R. M. Nisman, and L. Swell. 1982. Central role of high density lipoprotein in plasma free cholesterol metabolism. J. Clin. Invest. 70:105-116.

8. Hirsch, J., and E. H. Ahrens, Jr. 1958. The separation of complex lipid mixtures by the use of silicic acid chromatography. J. Biol. Chem. 233:311-320.

9. Sperry, W., and M. Webb. 1950. Revision of Schoenheimer-Sperry method for cholesterol determination. J. Biol. Chem. 187:97-106.

10. Noble, R. P. 1968. Electrophoretic separation of plasma lipoproteins in agarose gel. J. Lipid Res. 9:693-700. 
11. Burstein, M., and H. R. Scholnick. 1973. Lipoprotein-polyanionic-metal interactions. In Advances in Lipid Research. R. Paoletti and D. Kritchevsky, editors. Academic Press, New York. 11:67-108.

12. Folch, J., M. Lees and D. H. Sloan-Stanley. 1957. A simple method for the isolation and purification of total lipids from animal tissues. J. Biol. Chem. 226:497-509.

13. Schwartz, C. C., Z. R. Vlahcevic, L. G. Halloran, R. Nisman, and L. Swell 1977. Evidence for a common hepatic cholesterol precursor site for cholic and chenodeoxycholic acid synthesis in man. Proc. Soc. Exp. Biol. Med. 156:261264.

14. Nilsson, A., and D. B. Zilversmit. 1972. Fate of intravenously administered particulate and lipoprotein cholesterol in the rat. J. Lipid Res. 13:32-37.

15. Schwartz, C. C., L. G. Halloran, Z. R. Vlahcevic, D. H. Gregory, and L. Swell. 1978. High and low density lipoprotein metabolism in man: preferential utilization of HDL free cholesterol by the liver for biliary cholesterol secretion. Science (Wash. DC). 200:62-64.

16. Schwartz, C. C., M. Berman, Z. R. Vlahcevic, and L. Swell. 1982. Multicompartmental analysis of cholesterol metabolism in man: quantitative kinetic evaluation of precursor sources and turnover of high density lipoprotein cholesterol esters. J. Clin. Invest. 70:863-876.

17. Eisenberg, S. 1984. High density lipoprotein metabolism. J. Lipid Res. 25:1017-1045.

18. Langer, T., W. Strober, and R. I. Levy. 1972. The metabolism of low density lipoprotein in familial type II hyperlipidemia. J. Clin. Invest. 51:15281536.

19. Blum, C. B., R. I. Levy, S. Eisenberg, M. Hall III, R. H. Goebel, and M. Berman. 1977. High density lipoprotein metabolism in man. J. Clin. Invest. 60:795-807.

20. Zech, L. A. 1982. Sensitivity in compartmental models. In Lipoprotein Kinetics and Modeling. Berman, M., S. M. Grundy, and B. V. Howard, editors. Academic Press, New York. 471-480.
21. Samuel, P., and W. Perl. 1970. Long-term decay of serum cholesterol radioactivity: body cholesterol metabolism in normals and in patients with hyperlipoproteinemia and atherosclerosis. J. Clin. Invest. 49:346-357.

22. Smith, F. R., R. B. Dell, R. P. Noble, and D. S. Goodman. 1976. Parameters of the three-pool model of the turnover of plasma cholesterol in normal and hyperlipidemic humans. J. Clin. Invest. 57:137-148.

23. Lange, Y. 1992. Tracking cell cholesterol with cholesterol oxidase. $J$. Lipid Res. 33:315-320.

24. Lange, Y., and T. L. Steck. 1985. Cholesterol-rich intracellular membranes: a precursor to the plasma membrane. J. Biol. Chem. 260:15592-15597.

25. Urbani, L., and R. D. Simoni. 1990. Cholesterol and vesicular stomatitis virus $G$ protein take separate routes from the endoplasmic reticulum to the plasma membrane. J. Biol. Chem. 265:1919-1923.

26. Johnson, W. J., M. J. Bamberger, R. A. Latta, P. E. Rapp, M. C. Phillips, and G. H. Rothblat. 1986. The bidirectional flux of cholesterol between cells and lipoproteins: effects of phospholipid depletion of high density lipoprotein. J. Biol. Chem. 261:5766-5776.

27. Lange, Y., and B. V. Ramos. 1983. Analysis of the distribution of cholesterol in the intact cell. J. Biol. Chem. 258:15130-15134.

28. Straka, M. S., L. H. Junker, L. Zacarro, D. L. Zogg, S. Dueland, G. T. Everson, and R. A. Davis. 1990. Substrate stimulation of $7 \alpha$-hydroxylase, an enzyme located in the cholesterol-poor endoplasmic reticulum. J. Biol. Chem. 265:7145-7149.

29. Bjorkhem, I., and J.-E. Akerlund. 1988. Studies on the link between HMG-CoA reductase and cholesterol $7 \alpha$-hydroxylase in rat liver. J. Lipid Res. 29:136-143.

30. Jelinek, D. F., S. Andersson, C. A. Slaughter, and D. W. Russell. 1990. Cloning and regulation of cholesterol $7 \alpha$-hydroxylase, the rate-limiting enzyme in bile acid biosynthesis. J. Biol. Chem. 265:8190-8197.

31. Francone, O. L., C. J. Fielding, and P. E. Fielding. 1990. Distribution of cell-derived cholesterol among plasma lipoproteins: a comparison of three techniques. J. Lipid Res. 31:2195-2200. 